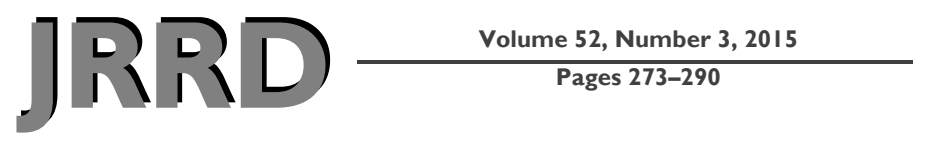

\title{
Effects of repetitive low-level blast exposure on visual systems and ocular structures
}

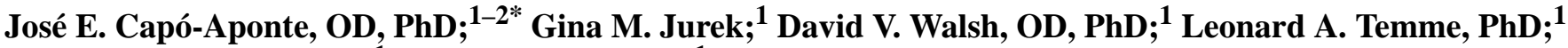 \\ William A. Ahroon, PhD; ${ }^{1}$ Daniel W. Riggs, MS $^{1}$ \\ ${ }^{1}$ Sensory Research Division, U.S. Army Aeromedical Research Laboratory, Fort Rucker, AL; ${ }^{2}$ Department of Optome- \\ try, Womack Army Medical Center, Fort Bragg, NC
}

\begin{abstract}
The purpose of this study was to determine whether repetitive exposure to low-level blasts during military breacher training produces acute and cumulative damage to the ocular tissues or visual system. The effects of low-level blast exposure on high-contrast visual acuity, contrast sensitivity, oculomotor function, color vision, visual field (VF), pupillary light reflex, corneal endothelial cell density (ECD), macular thickness, retinal nerve fiber layer thickness, and cup-to-disc ratio were assessed using a battery of standard clinical ophthalmic tests administered 10 times over a 2-year period. Data from nine male breacher instructors (Cadre) were compared with data from four male breacher engineers (Control). The Cadre group showed higher vertical deviation at near than the Control group over time. The VF mean deviation on the left eye tended to be worse in the Cadre group throughout the study, suggesting a decrease in VF sensitivity (Cadre: $-0.20+/-0.15 \mathrm{~dB}$; Control: $1.05+/-0.15 \mathrm{~dB} ; p=0.03$ ). The Cadre group had a reduced ECD (right eye: Cadre 2,478 cells $/ \mathrm{mm}^{2}$ vs Control 2,808 cells/ $\mathrm{mm}^{2}, p=0.02$; left eye: Cadre 2,562 cells $/ \mathrm{mm}^{2}$ vs Control 2,892 cells $/ \mathrm{mm}^{2}, p=0.03$ ). These results suggest that even low-level primary blast has the potential to produce occult eye injury.
\end{abstract}

Key words: accommodation, blast, Cone Contrast Test, endothelial cell density, frequency doubling technique, military, oculomotor function, pachymetry, specular microscopy, stereopsis.

\section{INTRODUCTION}

Throughout the past two decades, the extensive use of improvised explosive devices by enemy forces during urban warfare in the Middle East has resulted in a significant increase in blast-induced injuries to U.S. troops. Traumatic brain injury (TBI) resulting from blast exposure is recognized as the signature injury of recent combat operations, with over 300,000 cases of TBI reported

\begin{abstract}
Abbreviations: $\% \mathrm{CON}=$ percent of constriction, $\mathrm{ACV}=$ average constriction velocity, $\mathrm{ADV}=$ average dilation velocity, $\mathrm{C} / \mathrm{D}=$ cup-to-disc, $\mathrm{CCT}=$ Cone Contrast Test, CISS $=$ Convergence Insufficiency Symptoms Survey, CS = contrast sensitivity, D = diopter, $\mathrm{DoD}=$ Department of Defense, $\mathrm{ECD}=$ endothelial cell density, FDT $=$ frequency doubling technique, GPA $=$ Guided Progression Analysis ${ }^{\mathrm{TM}}, \mathrm{HCVA}=$ high-contrast visual acuity, HD-OCT $=$ high-definition optical coherence tomography, LAT = constriction latency, $\log \mathrm{MAR}=$ logarithm minimum angle of resolution, $\mathrm{MAX}=$ maximum diameter, $\mathrm{MCV}=$ maximum constriction velocity, $\mathrm{MD}=$ mean deviation, $\mathrm{MIN}=$ minimum diameter, $\mathrm{mTBI}=$ mild traumatic brain injury, $\mathrm{NVP}=$ near vertical phoria, $\mathrm{OD}=$ right eye, $\mathrm{OS}=$ left eye, $\mathrm{PLR}=$ pupillary light reflex, $\mathrm{PSD}=$ pattern standard deviation, $\mathrm{PSI}=$ pounds per square inch, $\mathrm{RNFL}=$ retinal nerve fiber layer, $\mathrm{SD}=$ standard deviation, $\mathrm{T} 75=75$ percent recovery time, $\mathrm{TBI}=$ traumatic brain injury, USAMRMC $=$ U.S. Army Medical Research and Materiel Command, USMC WTB MoES = U.S. Marine Corps' Weapons Training Battalion Methods of Entry School, VF = visual field.

*Address all correspondence to José E. Capó-Aponte, OD, PhD; Department of Optometry, Womack Army Medical Center, 2817 Reilly Rd, Stop A, Fort Bragg, NC 28310; 910907-8574; fax: 910-907-8612.
\end{abstract}

Email: jose.e.capoaponte.mil@mail.mil

http://dx.doi.org/10.1682/JRRD.2014.09.0204 
since 2000 [1]. Blast injury can be characterized as primary (exposure to overpressurization wave from blast), secondary (impact from blast and debris), tertiary (impact after displacement), or quaternary (burns, inhalation of toxins, hypoxia, and psychological effects) [2]. Exposure to primary blast has the potential to produce neuroophthalmic deficits by damaging the ocular tissue and areas of the brain that make vision possible.

Fluid-filled organs, such as the eyes, are particularly susceptible to primary blast injury. The primary blast shock wave can propagate through the different media of the eye globe and related orbital anatomical structures causing contusion to organs and tissue in the region [34]. Such ocular damage resulting from primary blast was initially described by Duke-Elder, and included subconjunctival hemorrhages, traumatic cataract, traumatic uveitis, secondary glaucoma, retinal edema, choroidal rupture, and macular lesions [5]. Damage to the eye and visual system may result from the mechanical damage of the tissue as well as disruption of the vascular system and cellular function or a combination of these [5]. Consistent with Duke-Elder's findings, careful clinical evaluation of returning servicemembers and Veterans found that blast overpressure can produce occult injuries to the ocular structures [6] as well as damage brain nuclei that control oculomotor functions and pupil response [7-11].

Attempts to recreate battlefield injury in the laboratory to expand the current knowledge regarding the type and extent of damage induced in the eye by primary blast in isolation have led to the development of animal and computational models using simulated blast overpressure. For instance, Petras et al. demonstrated for the first time the extent of irreversible neuro-ophthalmic trauma using a rodent model and simulated blast overpressure as low as 15 pounds per square inch (PSI) [12]. The documented damage extended from the retina to the central visual pathways [12]. They speculated that in humans such neurological deficits might lead to impairment of the oculomotor system, accommodation, and pupillary light reflex (PLR). A more recent study by Hines-Beard et al. showed corneal, lenticular, retinal, and optic nerve pathology using a primary blast mouse model to induce closed-globe blast injury when monitored for up to $28 \mathrm{~d}$ [13]. The observed damage was similar to those closedeye injuries recently described in Veterans [6]. Similarly, Zou et al. showed that primary blast induced severitydependent pathological changes in the retina of adult rats. This was demonstrated by the increased expression of proteins associated with inflammation and apoptosis.
These retinal changes were sustained for up to 3 wk after the initial blast exposure, suggesting a combination of acute and chronic damage to the retina [14].

Finally, computational models using finite element modeling have been characterized to simulate the propagation of blast waves through the orbit and attempt to explain the damage induced by the primary blast per se without the secondary or tertiary injury cofounder [3-4].

Given the high risk associated with any blast research using human subjects, the current knowledge regarding the effects of blast on the human visual system is based on retrospective clinical case descriptions potentially confounded by secondary or tertiary injury mechanisms [11]. In addition, the understanding of the extent of visual dysfunction and damage to ocular structures by the blast wave has been hampered by the lack of a population exposed solely to primary blast. In an attempt to gain an understanding of the effects of primary blast on military personnel, collaborative research initiatives within the Department of Defense (DoD) have been established. The U.S. Marine Corps' Weapons Training Battalion Methods of Entry School (USMC WTB MoES), also known as the Breacher School, serves as the platform to train Marines in different techniques to breach structures during combat operations. The Breacher School provides a unique opportunity to prospectively study the effects of repetitive lowlevel primary blast in isolation of other trauma and effects, which is nearly impossible otherwise. While hundreds of Marines attend the relatively short course ( $3 \mathrm{wk}$ ) on an annual basis, the instructors of this course are exposed to thousands of controlled low-level blasts during their assignment to the Breacher School. A previous study limited to breacher students demonstrated a significant increase in hearing damage secondary to the 3 wk exposure to repetitive low-level blast [15]. Another study conducted in New Zealand found decreased neurocognitive performance as well as increased expression of serum brain biomarkers' levels and self-reported symptoms changes in breacher students after repetitive exposure to low-level blast [16]. These findings suggest that repetitive low-level blast can produce damage to ocular structures and the visual system. Consequently, the purpose of this study was to determine whether repeated exposure to lowlevel blast during breacher training produces acute and cumulative damage to ocular tissues or the visual system. To our knowledge, this is the first longitudinal study to prospectively evaluate the effect of repetitive exposure to low levels of primary blast in humans. 


\section{METHODS}

\section{Subjects}

Seventeen male Marine instructors assigned to the USMC WTB MoES located in Quantico, Virginia, participated in the study. Thirteen were breacher instructors (i.e., Cadre group) and the remaining four were breacher engineers (i.e., Control group). Each year, this Cadre group supervises six classes, each of which is $3 \mathrm{wk}$ long. During each class, the Marine trainees are instructed on how to use various weapons systems to breach doors, walls, and roofs of various compositions [17]. The majority of the training involves the use of explosives to produce blast entries through building structures (Figure 1). While all personnel are required to wear protective eyewear during training to prevent injuries from fragments and blunt impact, it is possible that damage to the visual system and the ocular structures is caused by blast wave exposure alone. During these classes, the trainees and instructors are exposed to repetitive low-level blast explosions that can exceed 6 PSI $(41 \mathrm{kPA}$ or $186 \mathrm{~dB}$ of peak sound pressure level). As a consequence of their training responsibilities, the Cadre group at the Breacher School are exposed to 500 to 600 low-level blasts each year of their 2 or 3 year assignment. The size of, number of, and distances from the blasts are well controlled by the nature of the training curriculum. Each class is separated by $3 \mathrm{wk}$ of "recovery" to rebuild the structures damaged during training. The engineers are responsible for rebuilding the damaged structures and are not exposed to blasts; therefore, we considered them the Control group. The study was approved by the U.S. Army Medical Research and Materiel Command (USAMRMC) Office of Research Protection. All subjects provided their informed consent before each data collection session.

\section{Procedure and Data Collection}

The baseline testing session was completed during the 3 wk recovery period before initiating the training cycle. Subsequent testing sessions were conducted during the last week of the course without altering the way the Cadre group typically conducted their training. Depending on the training iteration, each Cadre group member was exposed to approximately 12 to 15 blasts over the course of the day. The individual level of exposure varied

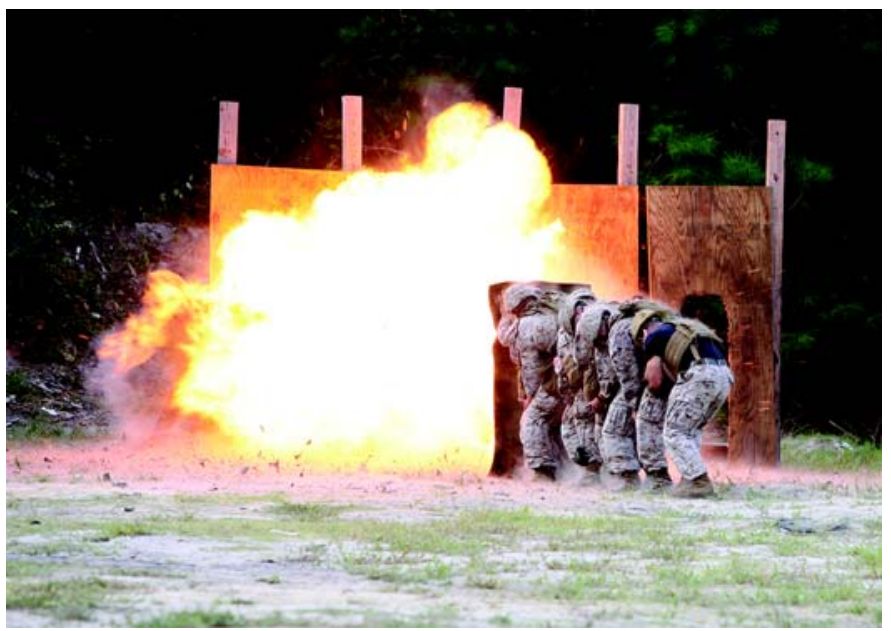

Figure 1.

U.S. Marine Corps breacher training configuration. During training exercise, trainees line up in "stack" at minimum safe distance that allows them immediate access to breached structure following detonation. Breacher instructor observes and provides instructions while standing at end of stack.

in any given training day based on size, number, and type of charge used as well as the distance from the detonation and the surrounding structures. The battery of standard, clinical ophthalmic tests described next was performed at the training site and administered multiple times over a $2 \mathrm{yr}$ period.

\section{High-Contrast Visual Acuity and Contrast Sensitivity}

The Rabin Supernormal Vision chart, which was mounted on a small illuminator cabinet (Precision Vision; La Salle, Illinois), was used to assess high-contrast visual acuity (HCVA) (ranging from -0.60 to 0.28 logarithm minimum angle of resolution [log MAR]) and contrast sensitivity (CS) (ranging from 2.00 to $0.05 \log$ CS). The tests were administered at $4 \mathrm{~m}$ distance under dim illumination. The tests were administered uncorrected since none of the subjects had a refractive error that required the use of distance or near vision correction.

\section{Oculomotor Function}

The Armed Forces Vision Tester (OPTEC-2300, Optec Inc; Lowell, Michigan) was used to measure vertical and horizontal phorias at near and distance as well as stereo acuity (depth perception). The static accommodation responses were measured using the WAM-5500 infrared open-field autorefractor (Grand Seiko Co Ltd; 
Hiroshima, Japan) [18]. In manual static mode, three baseline measurements were taken with the subject viewing the distance target $(4 \mathrm{~m})$ before assessing the static accommodative response function. The near target was mounted on the near-point rod starting at $50 \mathrm{~cm}$. Subjects were instructed to focus on the 20/30 line. Accommodative steady-state responses to a high-contrast reduced Snellen chart stimulus having a luminance of $36 \mathrm{~cd} / \mathrm{m}^{2}$ and positioned at $50,40,33,25$, and $20 \mathrm{~cm}$ were measured monocularly in a random sequence. For each stimulus and viewing condition, five measurements were obtained, and the average spherical equivalent refractive state was used for the analysis.

\section{Color Vision}

The Cone Contrast Test (CCT) (InnovaSystems Inc; Moorestown, New Jersey) was used to assess potential damage to retinal cones caused by primary blast exposure. Normal color vision depends on the full complement of long (red), middle (green), and short (blue) wavelength photoreceptors. The CCT provides a quantitative index of color ability specific for long, middle, and short cone-mediated vision [19-20]. The CCT score ranges from 0 to 100 . Individual scores for each cone type that were equal to or greater than 90 were considered normal, whereas values lower than 75 indicated a severe deficiency.

\section{Visual Field}

The Humphrey Matrix frequency doubling technique (FDT) perimeter (Carl Zeiss Meditec Inc; Dublin, California) was used to assess changes in visual field (VF) sensitivity. The VF sensitivity was measured by showing a $5^{\circ}$ target stimulus at various predetermined locations within the central $30^{\circ}$ field. The stimulus was an achromatic sinusoidal low spatial frequency grating that underwent counterphase flickering at a high temporal frequency [21]. The FDT threshold testing indicated the minimum CS needed to detect the stimulus at each tested location and was expressed in decibels of sensitivity [22]. FDT provides two global indices to summarize the VF results for threshold tests: mean deviation (MD) and pattern standard deviation (PSD). The MD indicated the deviation in overall VF sensitivity compared with normative data for an individual of the same age [22]. Negative MD values indicated that VF sensitivity was decreased compared with normative age-matched data. The PSD represents the evenness with which the VF loss was spread across the field of view following adjustments for any diffuse generalized sensitivity losses. The PSD is a value equal to or greater than zero. Higher values indicate a higher probability of a localized defect.

\section{Pupillary Light Reflex}

The PLR-200 monocular infrared pupillometer (NeurOptics; Irvine, California) was used to quantify PLR under mesopic conditions (approximately $3 \mathrm{~cd} / \mathrm{m}^{2}$ ) as previously described [8]. In brief, monocular PLR measurements were taken under binocular viewing conditions while the subject fixated with the nontested eye on a distance target $(4 \mathrm{~m})$. The pupillometer presented a $180 \mu \mathrm{W}$ light stimulus for $167 \mathrm{~ms}$. Eight PLR parameters were assessed: maximum diameter (MAX), minimum diameter (MIN), percent of constriction $(\% \mathrm{CON})$, constriction latency (LAT), average constriction velocity (ACV), maximum constriction velocity $(\mathrm{MCV}), 75$ percent recovery time (T75), and average dilation velocity (ADV). Monocular PLRs were recorded three times, and the average monocular values for each parameter were used for the analysis.

\section{Corneal Thickness and Endothelium Integrity}

The CellChek XL noncontact specular microscope (Konan Medical; Irvine, California) was used to measure corneal thickness (pachymetry) and to assess the integrity of the corneal endothelium. Three cornea endothelium parameters were assessed: endothelial cell density (ECD), coefficient of variation, and percent of hexagonal shape cells. The expected corneal ECD or cell count has been shown to vary with age [23-24]. The coefficient of variation represents the degree of variation in cell size also known as polymegethism [25]. Coefficient of variation values lower than 40 are considered normal [26]. The percent of hexagonal cells equal to or greater than 50 percent is considered normal.

\section{Retinal and Optic Nerve Integrity}

The Cirrus high-definition optical coherence tomography (HD-OCT) device (Carl Zeiss Meditec Inc) was used to assess the integrity of the macula, retinal nerve fiber layer (RNFL), and optic nerve as well as to monitor potential cumulative structural changes resulting from repetitive blast exposure. All images were obtained through undilated pupils. All scans can be compared against normative databases as well as against a patient's own baseline data. In addition, the HD-OCT device 
allows for visualization of the different layers of the retina, including the internal limiting membrane, photoreceptors, and retinal pigment epithelium. This layered mapping is informative not only for potential blastinduced changes to the retinal tissue but also for tracking the integrity of other ocular structures such as the optic nerve and the macula that could be affected by blast wave exposure [27].

\section{Convergence Insufficiency Symptoms Survey}

The 15-question pencil-and-paper Convergence Insufficiency Symptoms Survey (CISS) questionnaire was completed during each data collection session by selecting the frequency of the particular near vision symptom (Figure 2). The outcome measures were total score and individual question score. A total score higher than 20 is expected for symptomatic adults [28]. Each question had five possible answers with an associated value: always (4), frequently (3), sometimes (2), rarely (1), and never (0).

\section{Statistical Analysis}

Descriptive statistics (mean \pm standard deviation [SD]) were calculated for most of the outcome measures. The Student $t$-test was performed to analyze demographic data. Multivariate analysis of variance was performed to analyze all dependent variables. All significance levels were considered as $p<0.05$. Statistical analyses were performed with Excel (Microsoft Corporation; Redmond, Washington), SPSS version 20 (IBM Corporation;
Armonk, New York), and GraphPad Prism 6 (GraphPad Software Inc; San Diego, California) software.

\section{RESULTS}

All participants $(n=17)$ were male whose age ranged from 26 to 39 yr. Of the 13 Cadre group instructors, 4 were reassigned during the study and excluded from the analysis due to the lack of sufficient data. All nine remaining Cadre group members were newly assigned to the Breacher School when or after the study was initiated. Therefore, nine Cadre and four Control group members were included in the analysis. The mean age of the Cadre and Control groups was not significantly different ( $t$-test, $p=0.75)$. The mean \pm SD age for the Cadre and Control groups was $30.4 \pm 2.9$ and $31.0 \pm 3.6 \mathrm{yr}$, respectively. While all Cadre group members were exposed to similar level of blasts during their initial training as breachers, only one of the nine Cadre group members self-reported a significant blast exposure that occurred years before his assignment at the Breacher School. In contrast, none of the Control group members self-reported previous exposure to blast.

\section{High-Contrast Visual Acuity and Contrast Sensitivity}

The mean HCVA for repeated measures for both eyes and for both groups was not significantly different (right eye [OD]: $p=0.54$, Figure 3(a); left eye [OS]: $p=0.17$, Figure 3(b)). The mean HCVA throughout the study

1. Do your eyes feel tired when reading or doing close work?

2. Do your eyes feel uncomfortable when reading or doing close work?

3. Do you have headaches when reading or doing close work?

4. Do you feel sleepy when reading or doing close work?

5. Do you lose concentration when reading or doing close work?

6 . Do you have trouble remembering what you have read?

7. Do you have double vision when reading or doing close work?

8. Do you see the words move, jump, or appear to float on the page when reading or doing close work?

9. Do you feel you read slowly?

10. Do your eyes ever hurt when reading or doing close work?

11. Do your eyes ever feel sore when reading or doing close work?

12. Do you feel a "pulling" feeling around your eyes when reading or doing close work?

13. Do you notice the words blurring or coming in and out of focus when reading or doing close work?

14. Do you lose your place while reading or doing close work?

15. Do you need to re-read the same line of words?

Figure 2.

Questions included in Convergence Insufficiency Symptoms Survey questionnaire. 
(a)

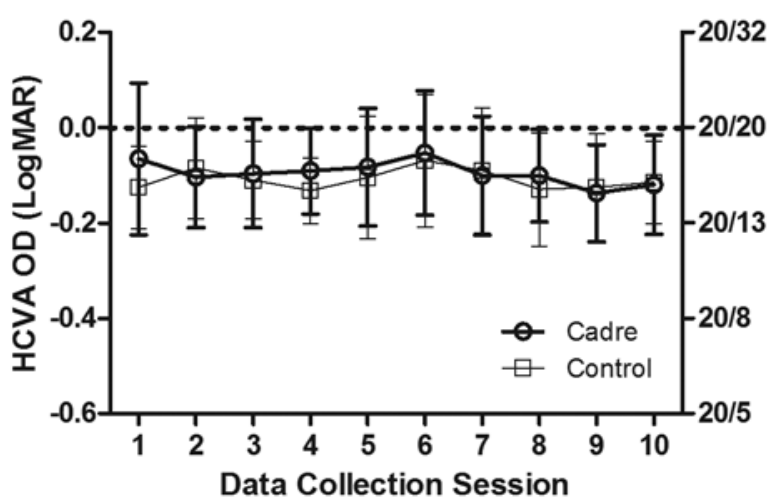

(c)

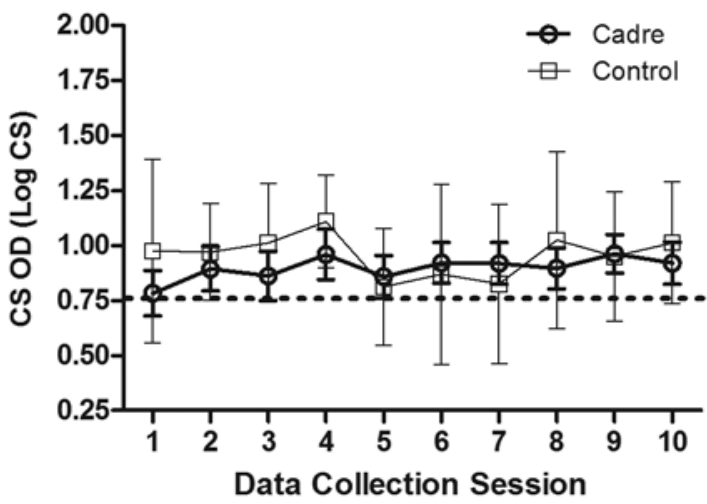

(b)

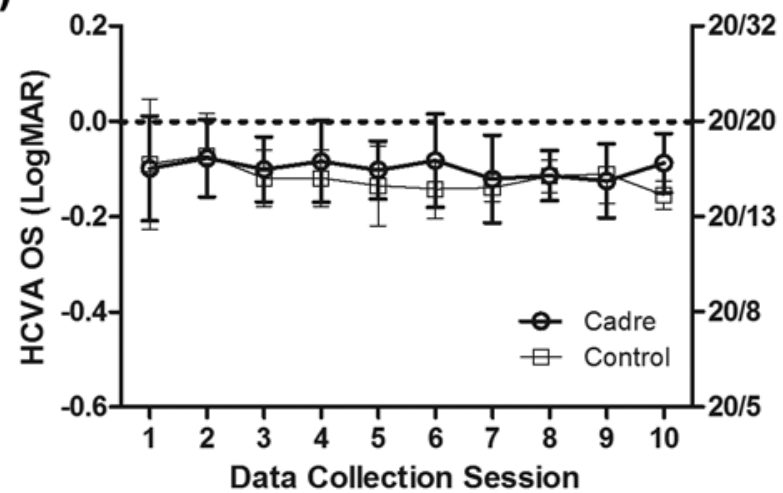

(d)

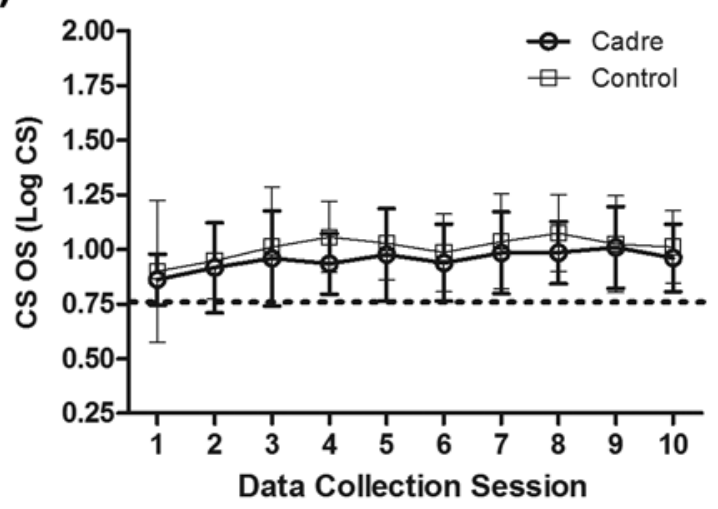

Figure 3.

Mean \pm standard deviation (SD) values for high-contrast visual acuity (HCVA) for (a) right eye (OD) and (b) left eye (OS). Values below dotted line are considered better than expected normative value (0.0 LogMAR or 20/20). Mean \pm SD contrast sensitivity (CS) for (c) OD and (d) OS. Values above dotted line are considered better than expected normative value $(0.75$ Log CS). MAR = minimum angle of resolution.

(Cadre: OD $-0.10 \pm 0.02 \operatorname{LogMAR}$ and OS $-0.10 \pm$ 0.02 LogMAR; Control: OD $-0.11 \pm 0.02$ LogMAR and OS $-0.12 \pm 0.03$ LogMAR) was lower (better) than the expected 0.0 LogMAR (20/20) for both eyes in each group. Similarly, the mean CS function for both groups (Cadre: OD $0.90 \pm 0.05 \log$ CS and OS $0.95 \pm 0.04 \log$ CS; Control: OD $0.95 \pm 0.09 \log$ CS and OS $1.01 \pm 0.05$ $\log \mathrm{CS}$ ) was higher (better) than the expected $0.75 \log \mathrm{CS}$ in both eyes, which remained generally unchanged throughout the study (OD: $p=0.32$, Figure 3(c); OS: $p=$ 0.57 , Figure 3(d)).

\section{Oculomotor Function}

The Cadre and Control groups were not statistically different from each other in terms of lateral and vertical phorias at distance and near. In addition, throughout the study their mean values remained within the normative Morgan values for lateral deviation at distance (i.e., between 2 esophoria and 3 exophoria, Figure 4(a)) and near (i.e., between 2 esophoria and 8 exophoria, Figure 4(b)) as well as distance vertical phoria and near vertical phoria (NVP) (i.e., $\leq 0.5$ diopter [D], Figure 4(c)-(d)). The Cadre group showed slightly higher vertical deviation at near than the Control group as time progressed. However, these differences were not statistically significant. As expected with appropriate near oculomotor alignment, the mean stereo acuity was better than the expected normative value of $40 \mathrm{~s}$ of arc for both groups (Figure 5), which did not significantly change over time for either group $(p=0.50)$.

The static monocular accommodation induced by randomly moving the near target at different predetermined 
(a)

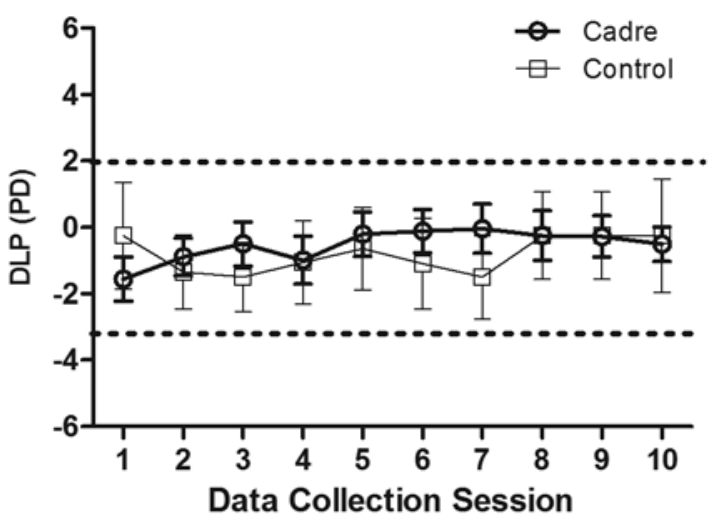

(c)

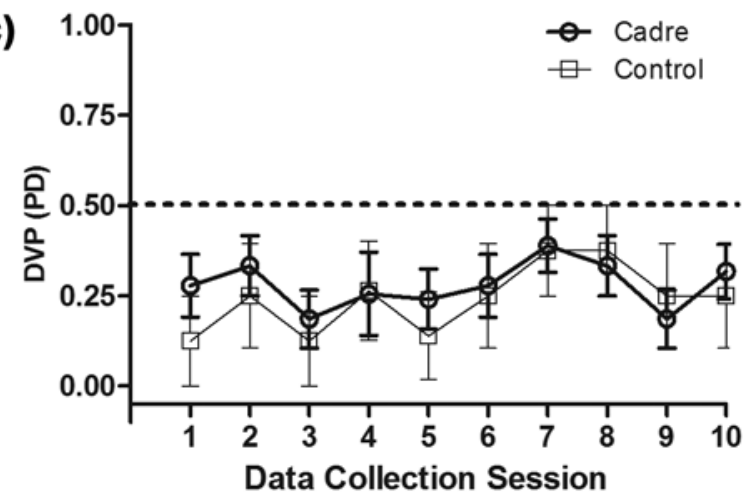

(b)

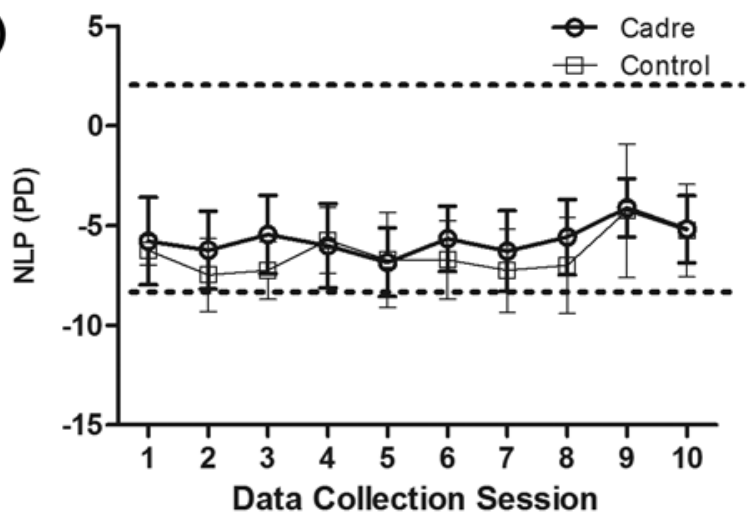

(d)

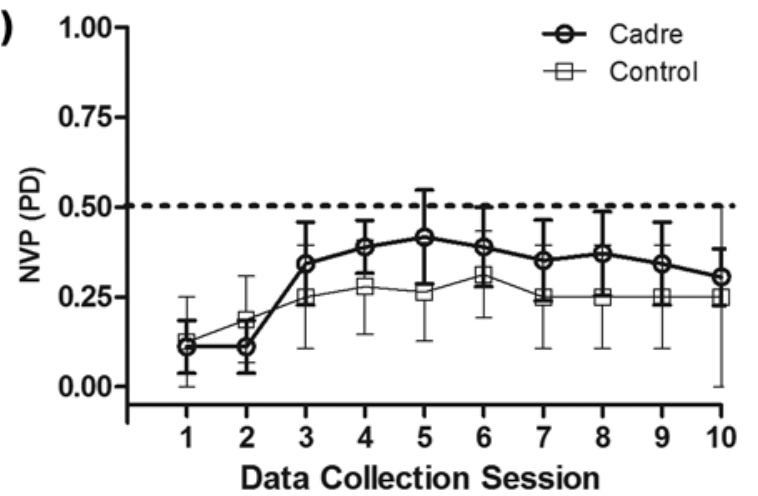

Figure 4.

Mean \pm standard deviation (SD) values for (a) distance lateral phoria (DLP) and (b) near lateral phoria (NLP). Values between dotted lines are considered within expected normative value. Negative values denote exophoria. Mean \pm SD values for (c) distance vertical phoria (DVP) and (d) near vertical phoria (NVP). Values below dotted line are within expected normative value. PD = prism diopter.

distances showed no significant difference between eyes or between groups throughout the study. The mean monocular accommodation was similar to the expected theoretical dioptric values based on the accommodative target distance for OD and OS: $50 \mathrm{~cm}$ (Figure 6(a)-(b)), $40 \mathrm{~cm}$ (Figure 6(c)-(d)), and $33 \mathrm{~cm}$ (Figure 6(e)-(f)). While the mean accommodative values of the stimulus located at $25 \mathrm{~cm}$ (Figure 6(g)-(h)) and $20 \mathrm{~cm}$ (Figure 6(i)-(j)) were slightly lower than expected values $(-4.0$ and $-5.0 \mathrm{D}$, respectively) for both eyes, there was no significant difference between the two groups or throughout the duration of the study. Table 1 summarizes the mean values.

\section{Color Vision}

The mean CCT scores for the red (Figure 7(a)-(b)), green (Figure 7(c)-(d)), and blue (Figure 7(e)-(f)) cones for both groups were within the CCT normal range (i.e., $\geq 90$ ). The mean scores did not change over the length of

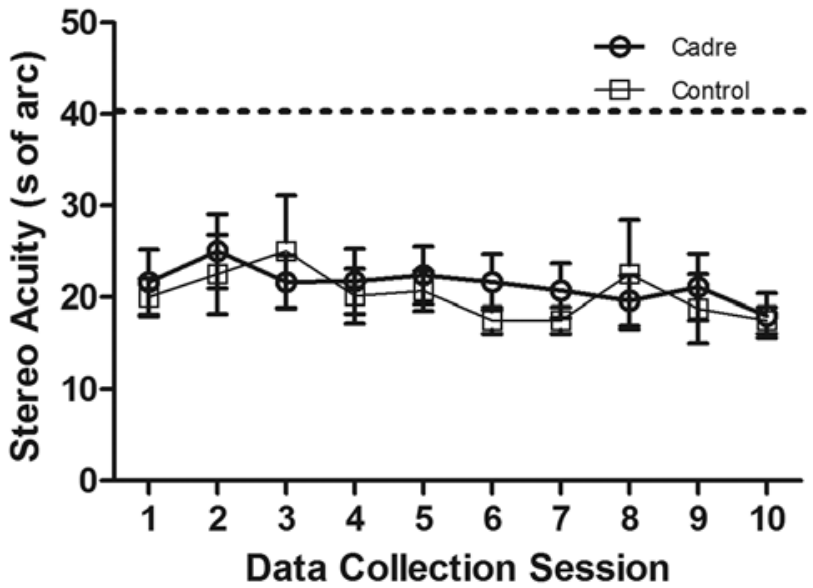

Figure 5.

Mean \pm standard deviation values for near stereopsis. Values below dotted line are considered within expected normative value (40 s of arc). 


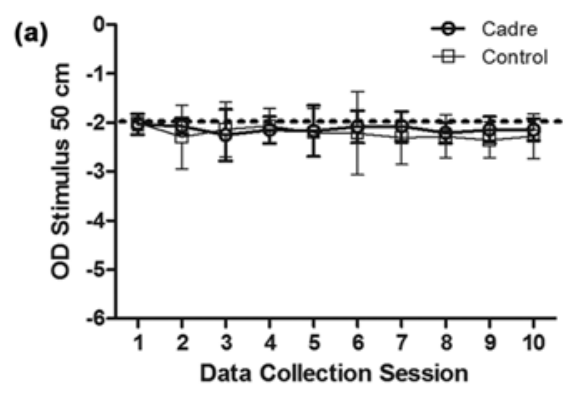

(c)

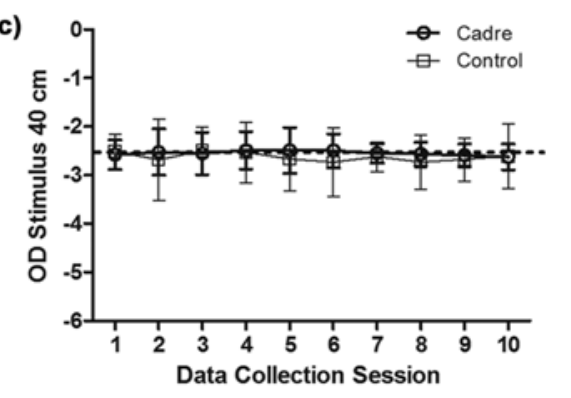

(e)

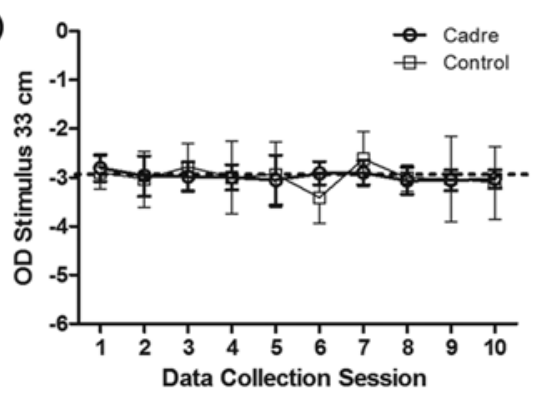

(g)

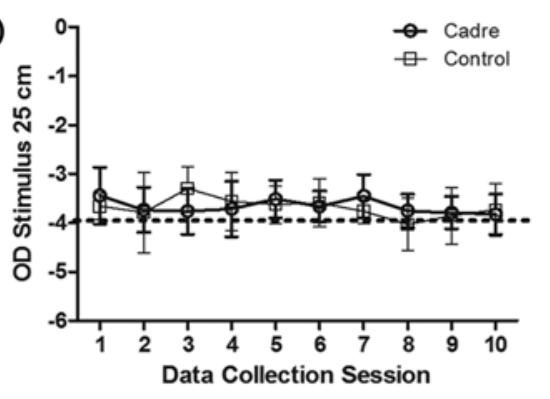

(i)

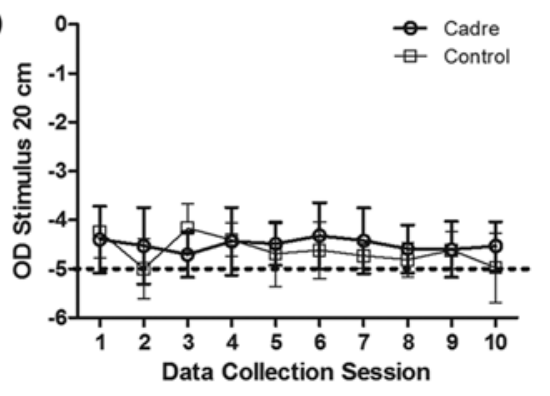

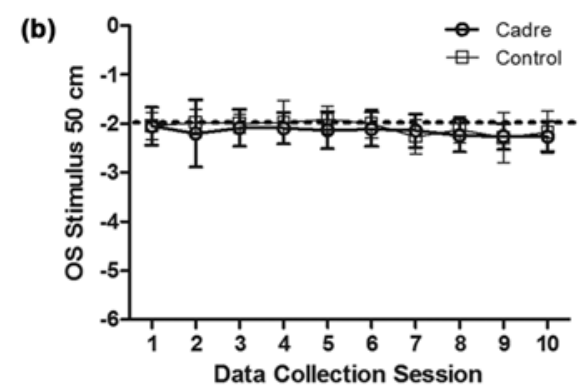

(d)

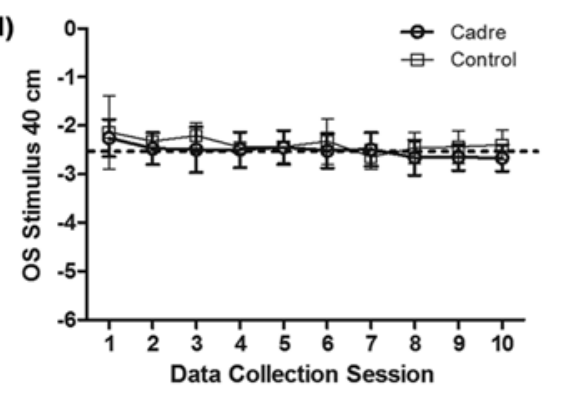

(f)

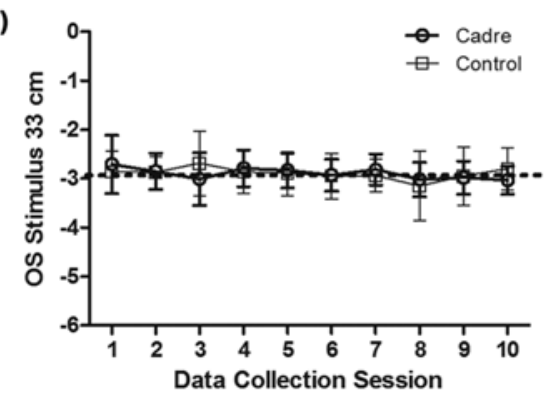

(h)

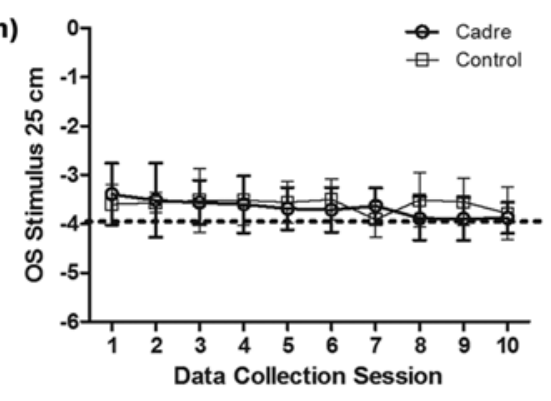

(j)

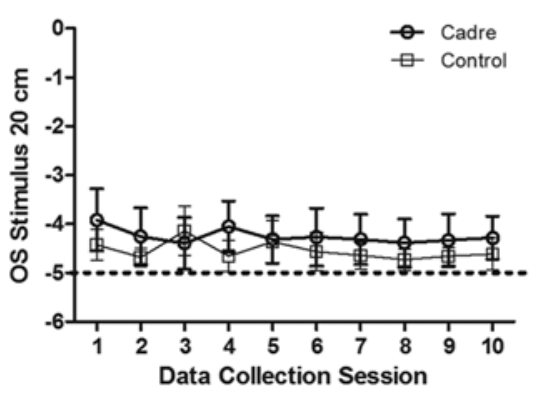

Figure 6.

Mean \pm standard deviation values for monocular accommodation induced by static accommodative target located at (a)-(b) 50 , (c)(d) 40, (e)-(f) 33, (g)-(h) 25, and (i)-(j) $20 \mathrm{~cm}$. Values below dotted line are within expected normative value. OD = right eye, OS = left eye. 
Table 1.

Between-group mean \pm standard deviation dioptric values for monocular accommodation resulting from static accommodative target located at indicated distance.

\begin{tabular}{|c|c|c|c|c|}
\hline Stimulus Distance (cm) & Eye & Cadre & Control & $p$-Value \\
\hline \multirow[t]{2}{*}{50} & OD & $-2.13 \pm 0.07$ & $-2.22 \pm 0.11$ & 0.69 \\
\hline & OS & $-2.16 \pm 0.08$ & $-2.08 \pm 0.13$ & 0.66 \\
\hline 40 & OD & $-2.55 \pm 0.05$ & $-2.63 \pm 0.09$ & 0.71 \\
\hline \multirow[t]{2}{*}{33} & OD & $-2.98 \pm 0.08$ & $-2.91 \pm 0.17$ & 0.76 \\
\hline & OS & $-2.90 \pm 0.11$ & $-2.90 \pm 0.12$ & 0.99 \\
\hline \multirow[t]{2}{*}{20} & OD & $-4.50 \pm 0.11$ & $-4.63 \pm 0.28$ & 0.66 \\
\hline & OS & $-4.25 \pm 0.15$ & $-4.55 \pm 0.18$ & 0.72 \\
\hline
\end{tabular}

the study, indicating that the cone function was not affected by repetitive low-level blast exposure. One of the Control group members was excluded from the analysis since he has a known severe green-color deficiency (deuteranomaly), which was confirmed by the CCT (OD: $48.75 \pm 2.33$; OS: $50.63 \pm 1.57$ ). Table 2 summarizes the mean values.

\section{Visual Field}

Two global indices were calculated by the FDT to summarize the VF sensitivity deviation based on its normative database. The VF MD for the OD tended to be less positive (worse) for the Cadre group (Figure 8(a)), but the difference was not statistically significant (Cadre: $0.39 \pm 0.90 \mathrm{~dB}$; Control: $1.06 \pm 0.12 \mathrm{~dB} ; p=0.16$ ). However, the VF MD value for the OS in the Cadre group was slightly more negative throughout the study (Figure 8(b)), suggesting a generalized decrease in VF sensitivity (Cadre: $-0.20 \pm 0.15 \mathrm{~dB}$; Control: $1.05 \pm 0.15 \mathrm{~dB} ; p=$ 0.03). On the other hand, the PSD values for both eyes were higher than expected (Figure 8(c)-(d)), but they were not significantly different between the groups (OD: Cadre $2.65 \pm 0.05 \mathrm{~dB}$ and Control $3.00 \pm 0.06 \mathrm{~dB}, p=$ 0.17; OS: Cadre $2.78 \pm 0.05 \mathrm{~dB}$ and Control $3.03 \pm 0.04 \mathrm{~dB}$, $p=0.29$ ). Higher PSD values are indicative of increased probability for localized VF defects.

\section{Pupillary Light Reflex}

The mean \pm SD values for all eight PLR parameters (MAX, MIN, \%CON, LAT, ACV, MCV, T75, and ADV) were not significantly different between the two groups and remained relatively stable during the study (Figure 9). Table 3 summarizes the mean values.

\section{Corneal Thickness and Endothelium Integrity}

The mean corneal thickness during the study did not change for either of the groups with an average thickness of $540 \mu \mathrm{m}$, which is the expected corneal thickness (Figure 10(a)-(b)). None of the subjects underwent previous refractive surgery or wore contact lenses that could affect corneal thickness. On the other hand, both eyes showed that the Cadre group had a slight decline in corneal ECD (Figure 10(c)-(d)). Although significant, the overall cell density was only slightly lower than the expected values $\left(2,500-3,200\right.$ cells $\left./ \mathrm{mm}^{2}\right)$ for the subjects' age group included in the present study (26-39 yr) [23-24]. The mean coefficient of variation values for both eyes and groups were lower (better) than the expected value of 40 (Figure 10(e)-(f)) [26]. The Cadre group had a slightly lower mean percentage of hexagonal than the expected 50 percent hexagonal cells in both eyes (Figure 10(g)(h)). However, these values were not significantly different between the groups and were constant throughout the study. Table 4 summarizes the mean values.

\section{Retinal and Optic Nerve Integrity}

The integrity of the retina and optic nerve was analyzed using a similar paradigm as the one used by the Cirrus HD-OCT device Guided Progression Analysis ${ }^{\mathrm{TM}}$ (GPA). The GPA calculates and compares the average of the last two measurements with the average of the two initial baseline measurements. There was no statistically significant difference between baseline or optic nerve cup-to-disc (C/D) ratio for both subgroups (Figure 11(a)). Similarly, there was no effect on the RNFL thickness for any of the conditions (Figure 11(b)). The central macular thickness did not change compared with baseline 
(a)

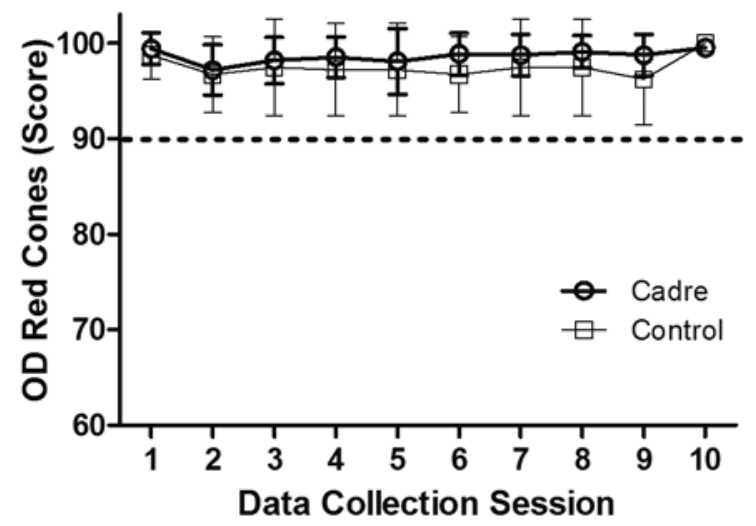

(c)

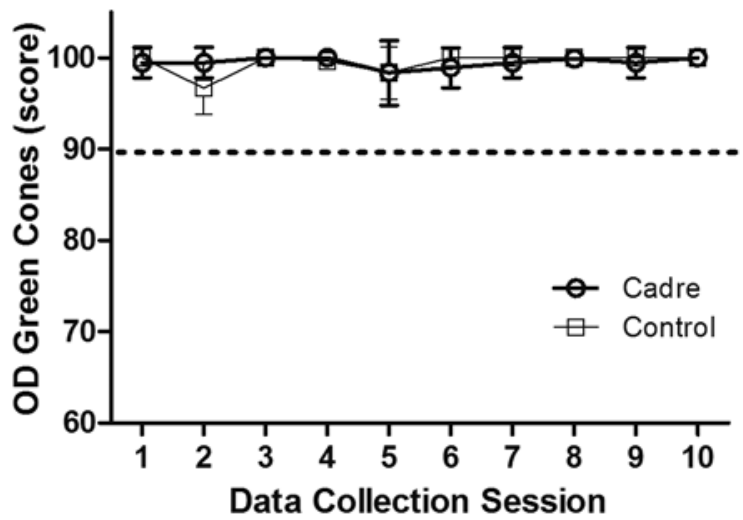

(e)

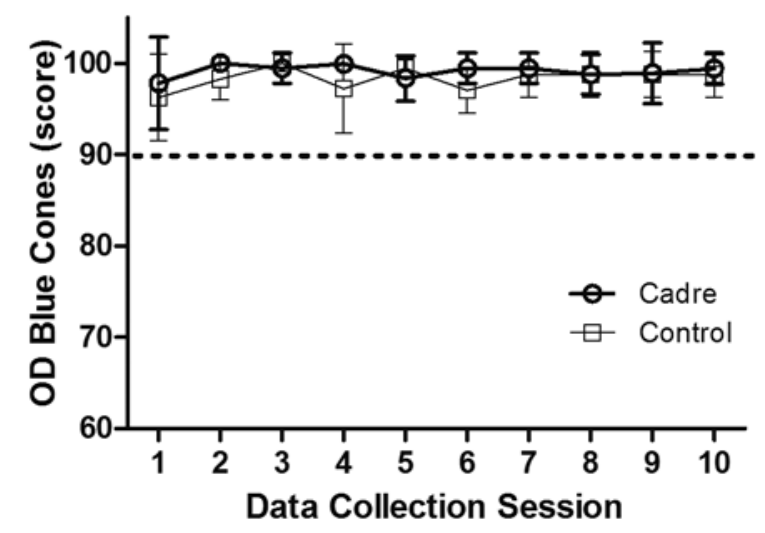

(b)

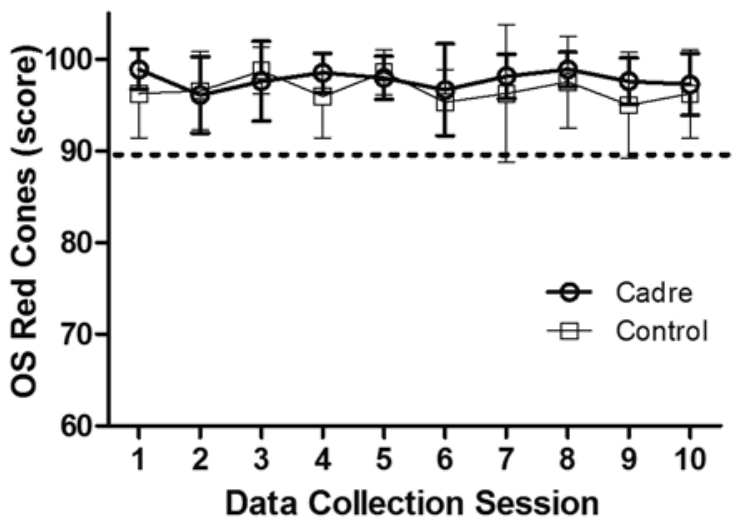

(d)

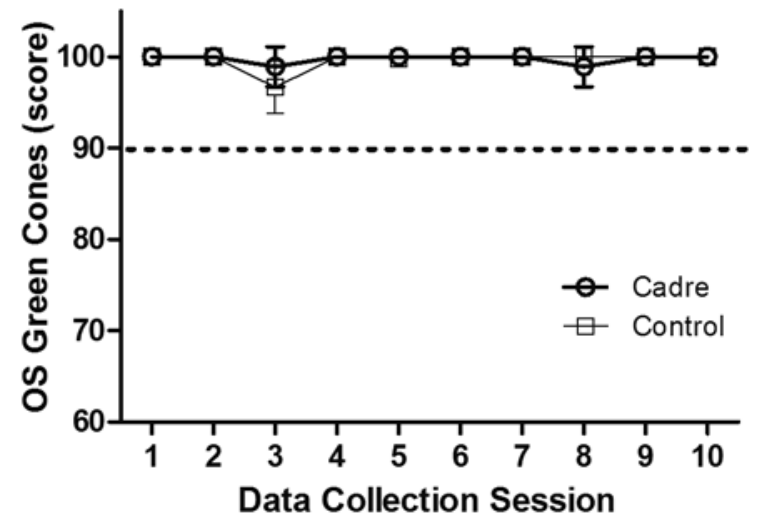

(f)

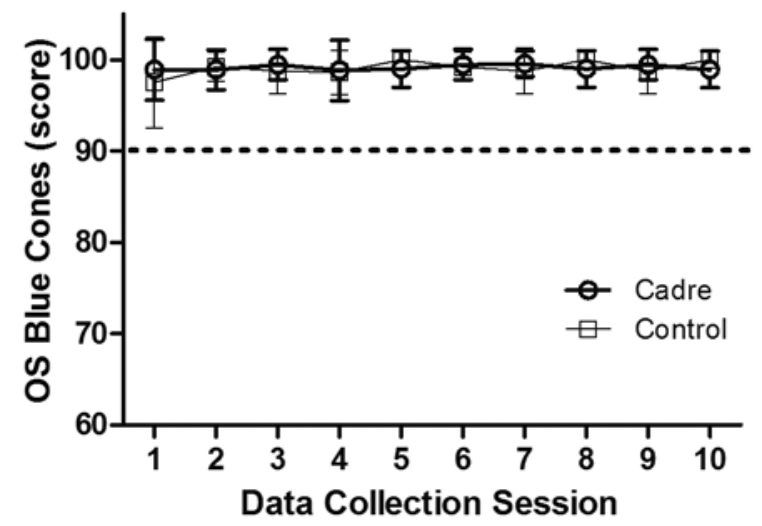

Figure 7.

Mean \pm standard deviation Cone Contrast Test (CCT) score indicative of monocular (a)-(b) red, (c)-(d) green, and (e)-(f) blue color cone function. Values above dotted line are within expected CCT normative values. OD = right eye, OS = left eye.

measurements, and there was no between-group difference for either eye (Figure 11(c)).

\section{Convergence Insufficiency Symptoms Survey}

To assess the possible symptoms related to near vision tasks, usually affected in those with some level of mild TBI (mTBI), the CISS questionnaire was adminis- tered during each data collection session. There was no significant difference in the CISS mean score between the Cadre and Control groups. The mean $\pm \mathrm{SD}$ total scores for the Cadre and Control groups were 9.0 \pm 6.8 and $9.2 \pm 7.1$, respectively $(p=0.48)$. Figure 12 shows the mean \pm SD score between-group comparisons for individual CISS questions (Figure 2). 
Table 2.

Group mean \pm standard deviation Cone Contrast Test scores for individual color photoreceptors.

\begin{tabular}{llllll}
\hline \multicolumn{1}{c}{ Cone Type } & Eye & Cadre & Control & p-Value \\
\hline Red & OD & $98.67 \pm 0.69$ & $97.55 \pm 1.01$ & 0.39 \\
Green & OS & $97.76 \pm 0.91$ & $96.65 \pm 1.30$ & 0.74 \\
& OD & $99.49 \pm 0.54$ & $99.46 \pm 1.10$ & 0.96 \\
Blue & OS & $99.78 \pm 0.47$ & $99.65 \pm 1.00$ & 0.59 \\
& OD & $99.14 \pm 0.70$ & $98.32 \pm 1.20$ & 0.35 & 0.95 \\
\hline OD = right eye, OS = left eye. & OS & $99.13 \pm 0.29$ & $99.08 \pm 0.79$ & \\
\hline
\end{tabular}

\section{DISCUSSION}

The acute and chronic visual problems experienced by servicemembers and Veterans following blast exposure are frequent and often complex [6-8,10,29-30]. While expo-
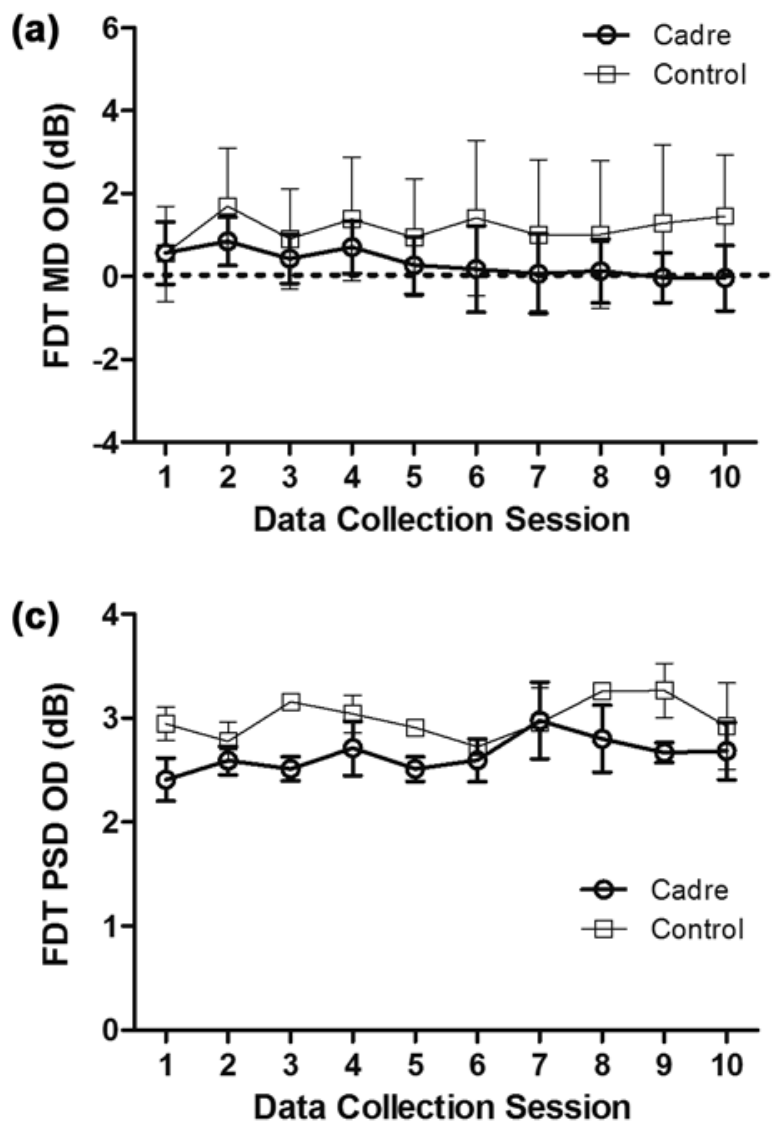

sure to low-level blast was not expected to induce an mTBI, we hypothesized that the cumulative effects of repetitive low-level blasts could produce damage to ocular structures and parts of the brain responsible for ocular motility and visual processing, which could induce mTBI-like
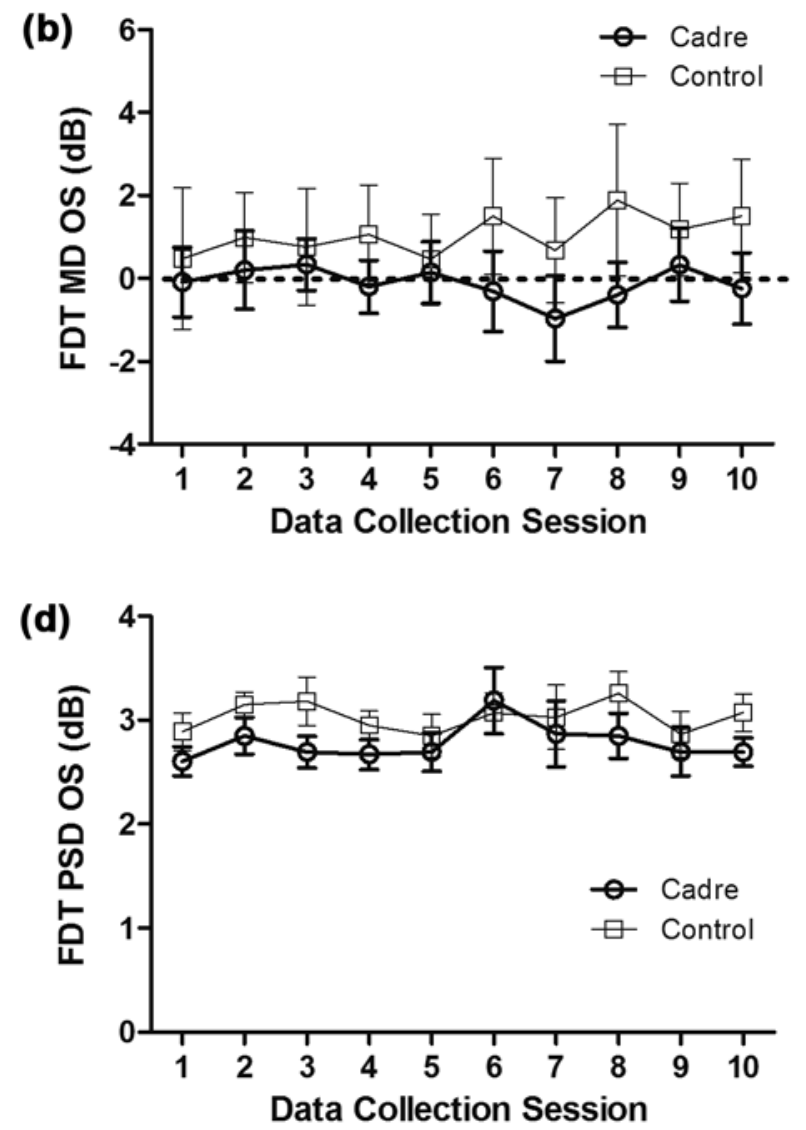

Figure 8.

Mean \pm standard deviation (SD) frequency doubling technique (FDT) mean deviation (MD) values for (a) right eye (OD) and (b) left eye (OS) documented during each data collection session. Values above dotted line (positive) are within expected FDT normative value. FDT pattern SD (PSD) values for (c) OD and (d) OS documented during each data collection session. Values higher than 0 indicate deviation from normal and increased probability of localized defect. 

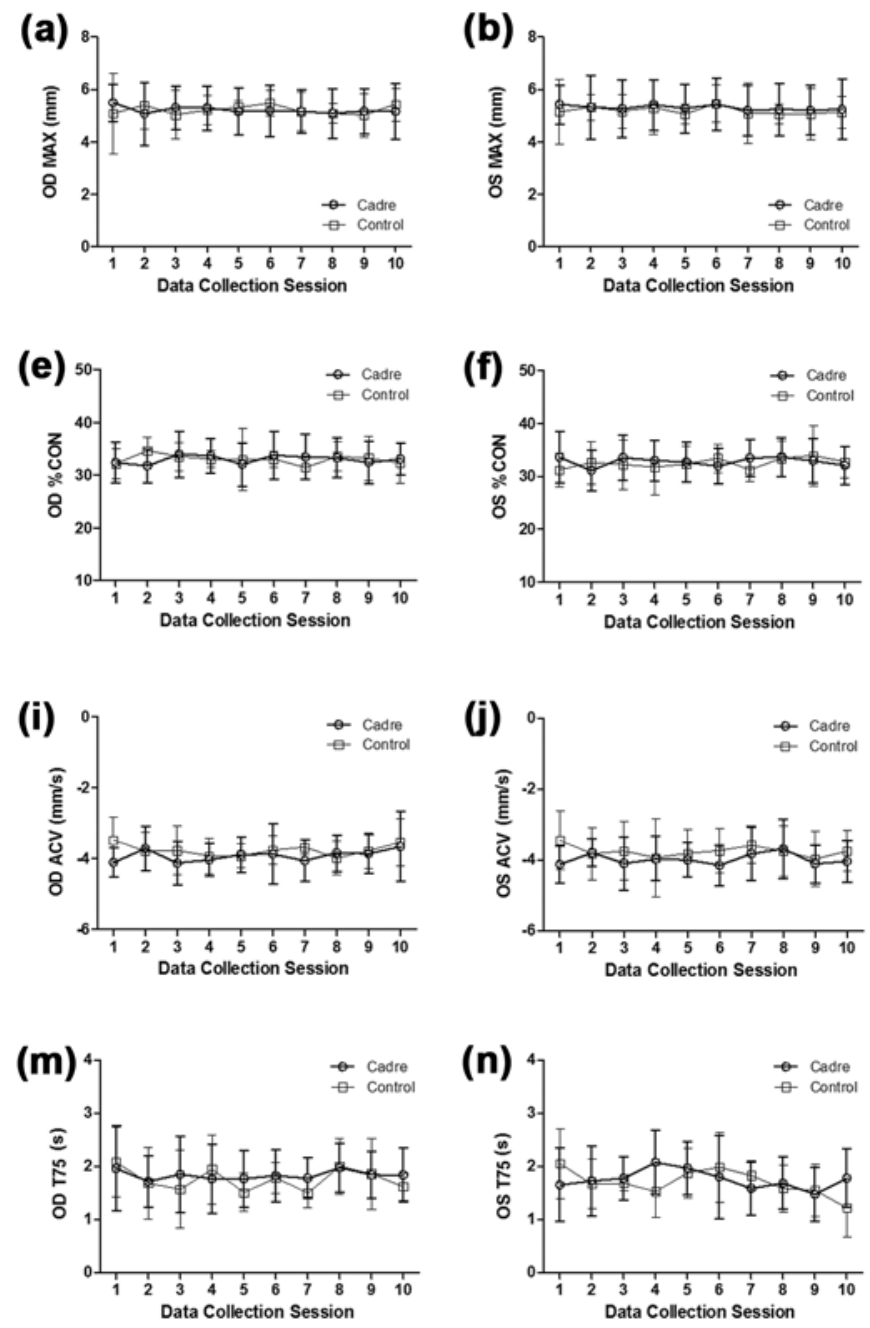
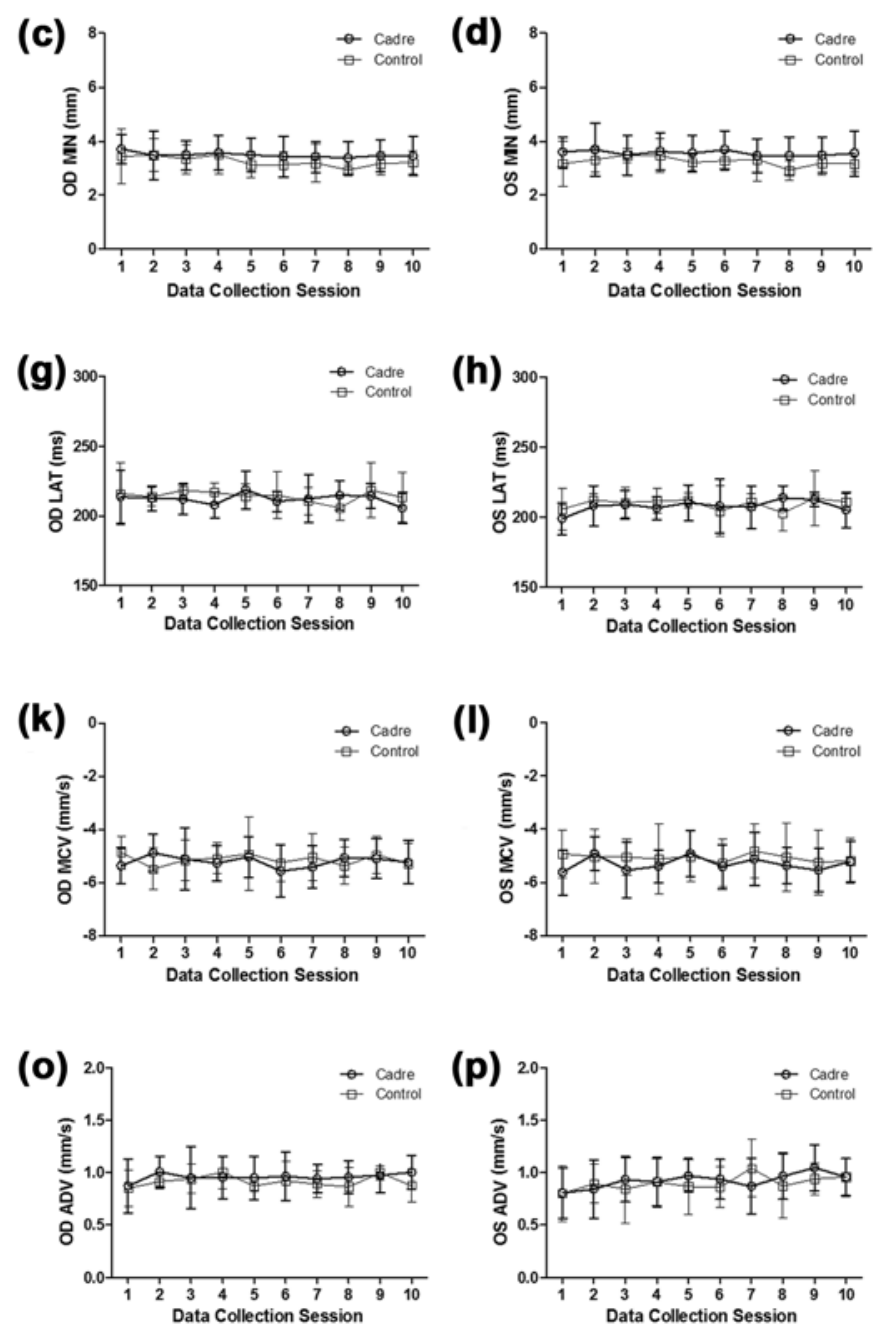

Figure 9.

Mean \pm standard deviation monocular pupillary light reflex values: (a)-(b) maximum diameter (MAX), (c)-(d) minimum diameter (MIN), (e)-(f) percent of constriction (\%CON), (g)-(h) constriction latency (LAT), (i)-(j) average constriction velocity (ACV), (k)-(l) maximum constriction velocity $(\mathrm{MCV}),(\mathbf{m})-(\mathbf{n}) 75$ percent recovery time $(\mathrm{T75})$, and $(\mathbf{o})-(\mathbf{p})$ average dilation velocity $(\mathrm{ADV})$. OD = right eye, OS = left eye.

symptoms. To validate our hypothesis, we employed a comprehensive battery of subjective and objective tests to assess visual functions and the integrity of ocular structures. The present study only found significant between-group differences for corneal ECD, vertical deviation, and general VF sensitivity. Despite these findings, all the test results in the experimental (Cadre) group were within, or slightly lower (worse), than normative value ranges defined for each test.

NVP was the only tested oculomotor function that appeared to be affected by the level of primary blast the Cadre group was exposed to during the study. While the Cadre group had a significant increase in NVP compared with the Control group, the values were still within the expected normative range (i.e., $\leq 0.5$ prism D). This correlates with this study population's lack of near vision symptoms determined by the CISS questionnaire. NVP is one of the most common oculomotor signs seen in servicemembers with blast-induced mTBI [7]. However, damage to the vestibular system could also account for the increased vertical deviation in the experimental (Cadre) group found in the present study [31-32]. A previous study by St. Onge et al. found some vestibular problems under similar training conditions, even after only 3 wk of exposure to the same level of repetitive blast [16]. 
Table 3.

Mean \pm standard deviation pupillary light reflex parameters.

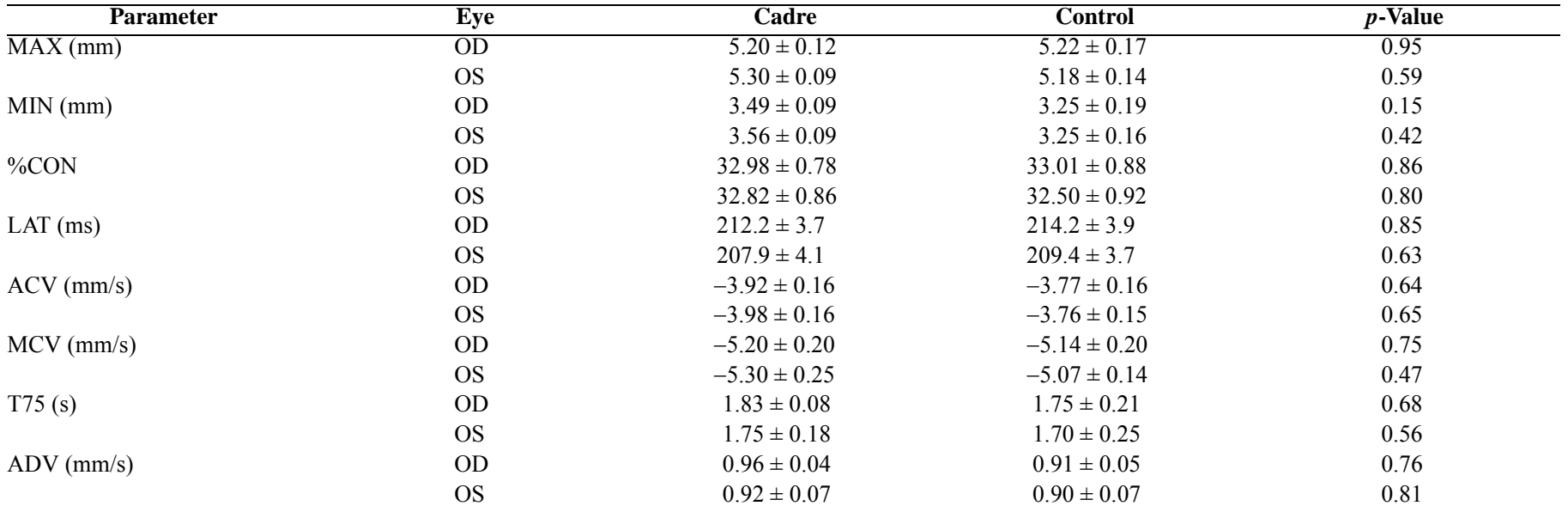

$\% \mathrm{CON}=$ percent of constriction, $\mathrm{ACV}=$ average constriction velocity, $\mathrm{ADV}=$ average dilation velocity, LAT $=$ constriction latency, MAX $=$ maximum diameter, $\mathrm{MCV}=$ maximum constriction velocity, $\mathrm{MIN}=$ minimum diameter, $\mathrm{OD}=$ right eye, $\mathrm{OS}=$ left eye, $\mathrm{T} 75=75$ percent recovery time.

The use of FDT perimetry detected a general decrease in VF sensitivity, based on MD values, that was higher for both eyes but only significant for OS in the Cadre group. The fact that one eye might be more affected than the other could be explained by the fact that the stack tends to face the charges off-center, which may result in injuring or affecting one eye more than the other. Interestingly, a recent study showed that scattered VF defects, similar to the ones observed in the present study, were the most common VF deficits associated with blastinduced mTBI, which is characterized by a generalized FDT MD decrease [33].

Different from other automated VF testing modalities, the low spatial temporal frequency stimulus used in FDT presumably stimulates the magnocellular pathway [21]. While there are no other studies describing FDT (a)

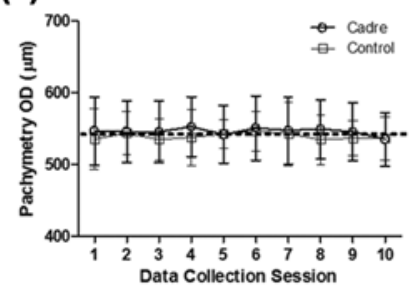

(e)

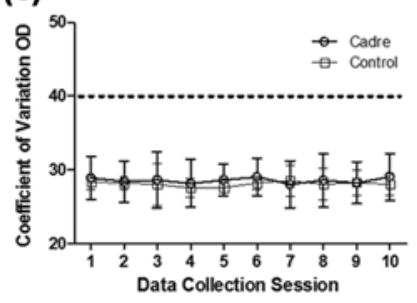

(b)

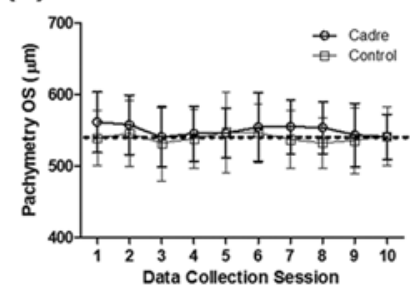

(f)

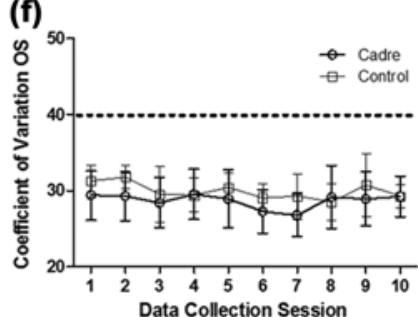

(c)

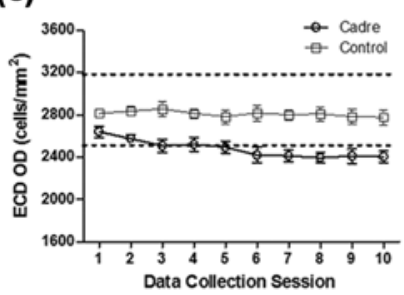

(g)

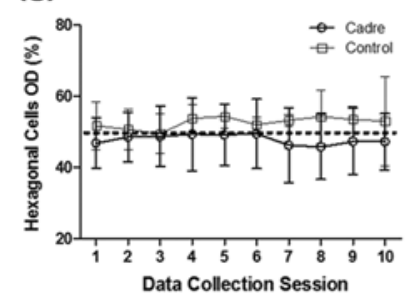

(d)

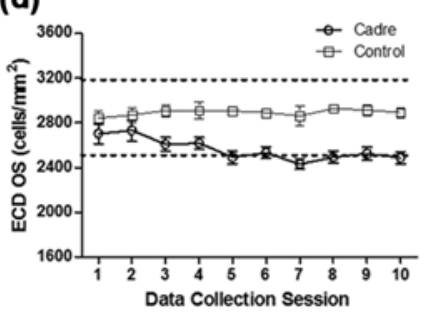

(h)

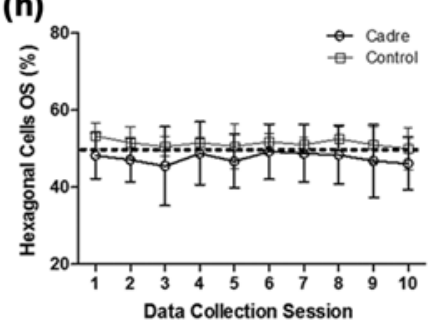

Figure 10.

Mean \pm standard deviation values for corneal parameters: (a)-(b) pachymetry, (c)-(d) endothelial cell density (ECD), (e)-(f) coefficient of variation, and (g)-(h) percent of hexagonal cells. Dotted lines indicate normative value. OD = right eye, OS = left eye. 
JRRD, Volume 52, Number 3, 2015

Table 4.

Mean \pm standard deviation of corneal parameters determined by specular microscopy.

\begin{tabular}{llllc}
\hline \multicolumn{1}{c}{ Parameter } & Eye & Cadre & Control & $p$-Value \\
\hline Corneal Thickness $(\mu \mathrm{m})$ & OD & $546.0 \pm 4.8$ & $539.1 \pm 1.4$ & 0.37 \\
& OS & $549.8 \pm 7.4$ & $539.6 \pm 5.7$ & 0.66 \\
Endothelial Cell Density $\left(\right.$ cells $\left./ \mathrm{mm}^{2}\right)$ & OD & $2,478 \pm 84.9$ & $2,808 \pm 25.2$ & $0.02^{*}$ \\
& OS & $2,562 \pm 98.8$ & $2,892 \pm 25.9$ & $0.03^{*}$ \\
Coefficient of Variation & OD & $28.54 \pm 0.4$ & $28.05 \pm 0.3$ & 0.35 \\
& OS & $28.67 \pm 0.9$ & $29.91 \pm 1.1$ & 0.42 \\
Hexagonal Cell Percentage & OD & $47.89 \pm 1.3$ & $52.62 \pm 1.6$ & 0.24 \\
& OS & $47.59 \pm 1.3$ & $51.39 \pm 1.0$ & 0.29 \\
\hline${ }^{*}$ Station
\end{tabular}

*Statistically significant.

$\mathrm{OD}=$ right eye, $\mathrm{OS}=$ left eye.

defects in blast-induced mTBI, one report described the application of FDT in detecting magnocellular pathway deficiencies commonly seen in glaucoma, saccadic dysfunction, and TBI [21]. Interestingly, the FDT MD and PSD values in the Control group were higher than those previously reported in a normal population [34]. It is possible that this discrepancy is due to the limited number of subjects in the Control group $(n=4)$.

In addition to subjective functional vision tests, this study included objective testing to assess the integrity of ocular tissue. While the OCT data revealed no significant difference between the groups in terms of RNFL thickness, central macular thickness, or optic nerve C/D ratio, specular microscopy data revealed a significantly lower corneal ECD in the Cadre group. The mean corneal ECD values for the Cadre group were slightly lower than the expected average ECD for the 26 to $39 \mathrm{yr}$ age group included in this study (i.e., 2,500-3,200 cells $/ \mathrm{mm}^{2}$ ), which is in agreement with the normal mean values for cornea thickness, percent of hexagonal cells, and coefficient of variation as well as the lack of visual symptoms. Decreased corneal ECD has been previously reported in Veterans who were exposed to a blast event [6]. Longitudinal follow-up will be needed to determine whether this could lead to premature corneal decompensation later in life.

It is worth mentioning that in terms of PLR, the mean values for all eight parameters for both groups were similar to those previously described for subjects who were not exposed to blasts (controls) [8]. Also, while CCT has not been used previously to assess the effect of ocular trauma, a previous study showed its sensitivity to detect color deficiencies resulting from acquired ocular disease processes [20]. Therefore, lack of a between-group difference is most likely due to the absence of damage to the retinal cones and not due to the CCT lack of sensitivity.
The main limitation of the study is the small sample size for each group, particularly for the Control group. However, since normative values exist for all of the outcome measures, the small size of the Control group should not necessarily invalidate the suggestive study results. While the study was able to recruit all the servicemembers assigned to the USMC WTB MoES, the number of subjects in the study was mainly limited by the number of personnel assigned to the Breacher School. Also given the lack of other experimental populations exposed to blast, this small size might be considered adequate.

\section{CONCLUSIONS}

Blast injuries to ocular structures and the visual system, with special emphasis on those injuries caused by the primary blast wave, are a significant concern among healthcare providers due to the high prevalence of blast injuries seen over the past two decades of conflict in the Middle East. The results from this study are suggestive that exposure to repetitive low-level primary blast may have detrimental effects on corneal ECD counts, NVP deviations, and general VF sensitivity. Despite these findings, all test results in the experimental (Cadre) group were within, or slightly lower (worse) than, the normative value ranges defined for each test. These findings show that the current levels of blast exposure used at the USMC WTB MoES appear to be safe. However, the fact that some tests indicated slight ophthalmic changes over time, or compared with the Control group, emphasizes the importance to healthcare providers in performing select ophthalmic tests in those individuals who have been exposed to repetitive blasts without classical symptoms or signs of ocular or visual system damage. 
(a)

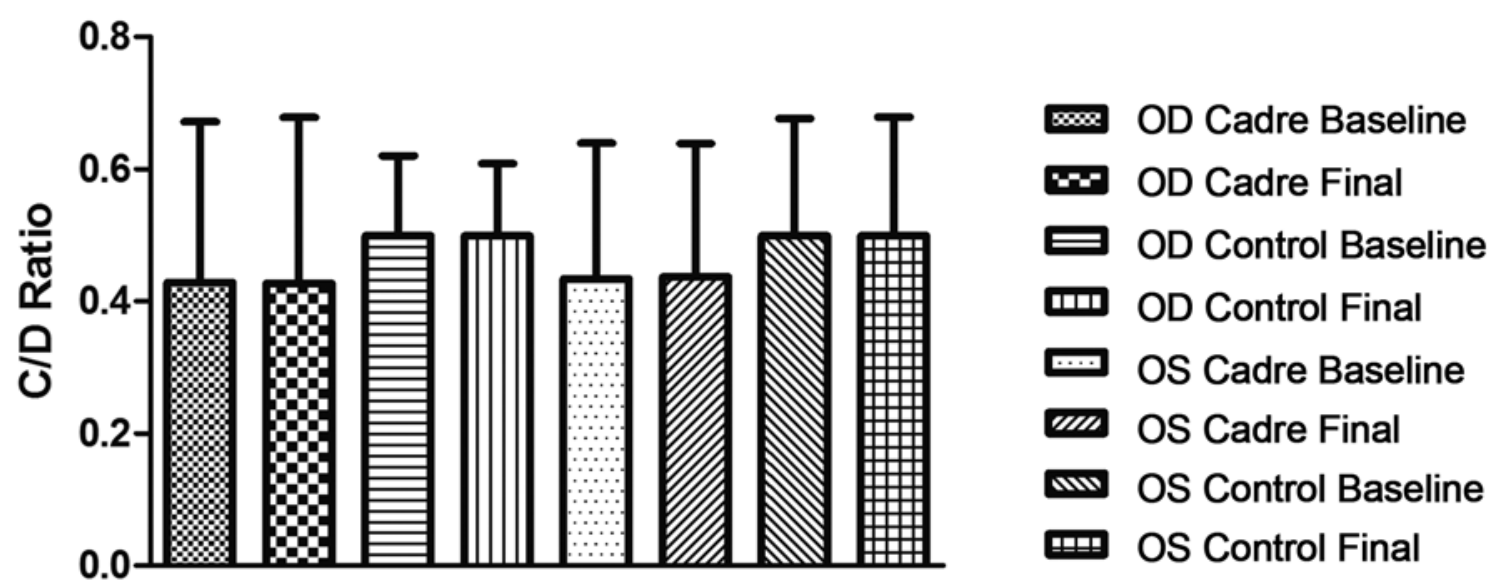

(b)

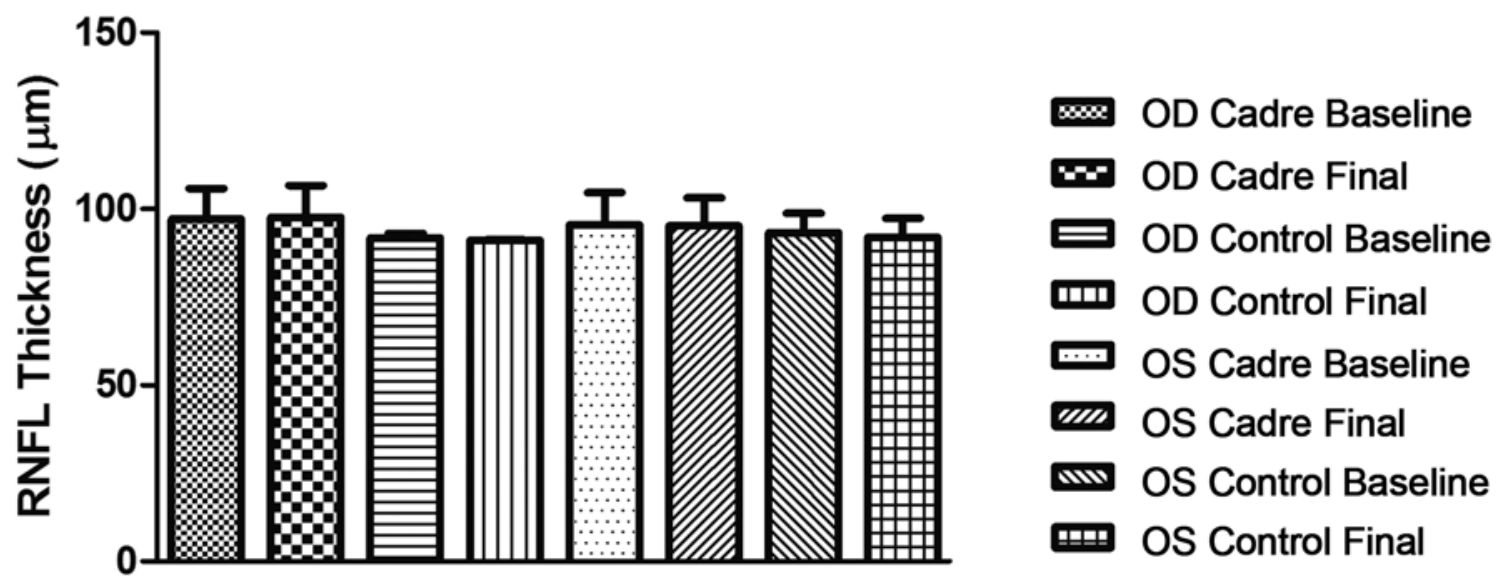

(c)

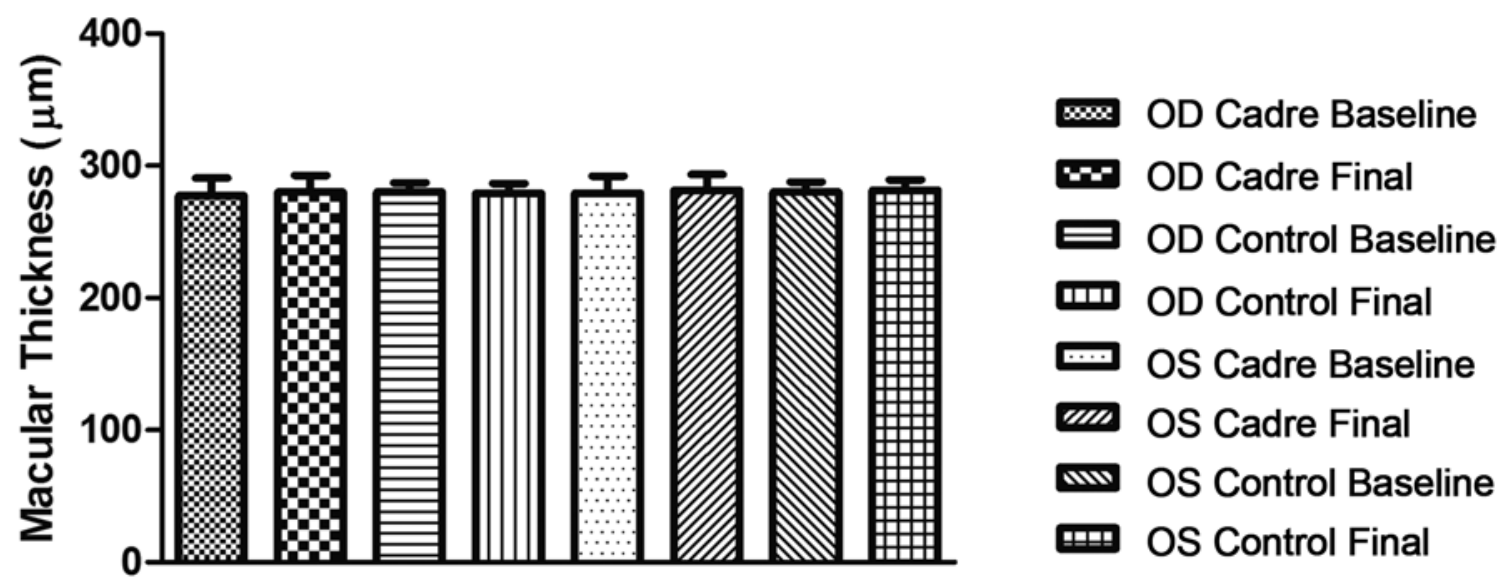

Figure 11.

Mean \pm standard deviation values for average two baseline and two final measurements for (a) cup-to-disc (C/D) ratio, (b) retinal nerve fiber layer (RNFL) thickness, and (c) central macular thickness. OD = right eye, OS = left eye. 


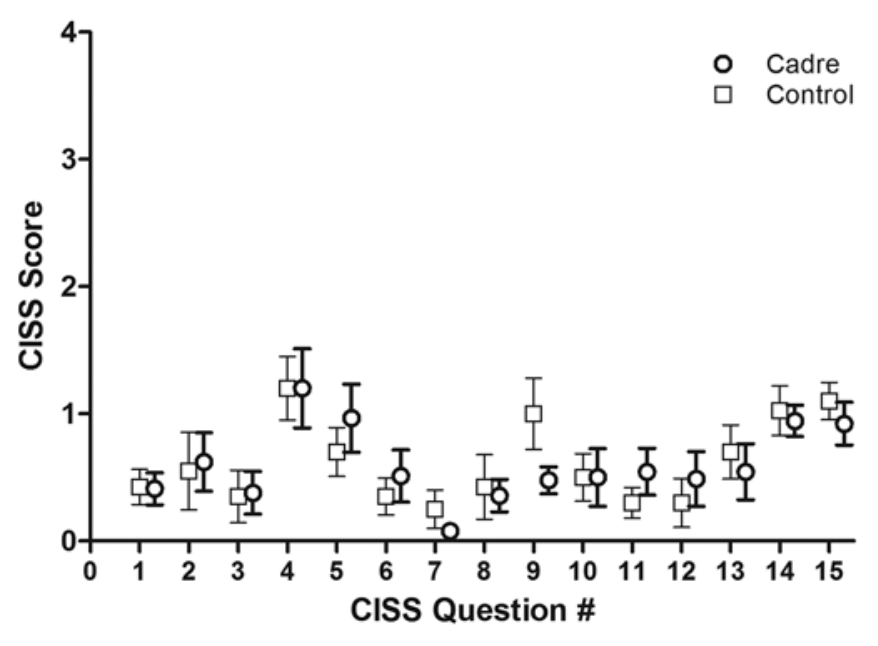

Figure 12.

Mean \pm standard deviation values for each Convergence Insufficiency Symptoms Survey (CISS) question. Figure 2 lists individual questions. Each CISS question was scored based on associated value: always (4), frequently (3), sometimes (2), rarely (1), and never (0).

\section{ACKNOWLEDGMENTS}

\section{Author Contributions:}

Study concept and design: J. E. Capó-Aponte, L. A. Temme, W. A. Ahroon.

Acquisition of data: G. M. Jurek, J. E. Capó-Aponte.

Analysis and interpretation of data: L. A. Temme, D. W. Riggs,

J. E. Capó-Aponte, D. V. Walsh.

Drafting of manuscript: J. E. Capó-Aponte, D. V. Walsh,

L. A. Temme.

Critical revision of manuscript for important intellectual content:

J. E. Capó-Aponte, L. A. Temme, W. A. Ahroon, G. M. Jurek,

D. V. Walsh.

Statistical analysis: L. A. Temme, D. W. Riggs, J. E. Capó-Aponte.

Obtained funding: J. E. Capó-Aponte, W. A. Ahroon.

Administrative, technical, or material support: G. M. Jurek,

W. A. Ahroon, L. A. Temme, D. V. Walsh.

Study supervision: J. E. Capó-Aponte, L. A. Temme, W. A. Ahroon.

Financial Disclosures: The authors have declared that no competing interests exist.

Funding/Support: This material was based on work supported by the U.S. Army Aeromedical Research Laboratory (Dr. Capó-Aponte) and DoD Intramural War Supplemental Program (grant W81XWH-09-20192) (Dr. Ahroon). This research was also sponsored in part by the appointment to the Postgraduate Research Participation Program at the U.S. Army Aeromedical Research Laboratory administered by the Oak Ridge Institute of Science and Education through an interagency agreement with the U.S. Department of Energy and USAMRMC.
Institutional Review: The study protocol was approved by the USAMRMC Institutional Review Board. Informed written consent was obtained from all participants before each data collection session. Participant Follow-Up: The authors do not plan to notify study participants of the publication of this article.

Disclaimer: The views, opinions, and/or findings contained in this article are those of the author(s) and should not be construed as an official Department of the Army position, policy, or decision, unless so designated by other official documentation.

\section{REFERENCES}

1. DoD worldwide numbers for TBI [Internet]. Silver Spring (MD): Defense and Veterans Brain Injury Center; 2014. Available from: http://dvbic.dcoe.mil/dod-worldwide-numbers-tbi

2. Nakagawa A, Manley GT, Gean AD, Ohtani K, Armonda R, Tsukamoto A, Yamamoto H, Takayama K, Tominaga T. Mechanisms of primary blast-induced traumatic brain injury: Insights from shock-wave research. J Neurotrauma. 2011;28(6):1101-19. [PMID:21332411] http://dx.doi.org/10.1089/neu.2010.1442

3. Rossi T, Boccassini B, Esposito L, Clemente C, Iossa M, Placentino L, Bonora N. Primary blast injury to the eye and orbit: Finite element modeling. Invest Ophthalmol Vis Sci. 2012;53(13):8057-66. [PMID:23111614] http://dx.doi.org/10.1167/iovs.12-10591

4. Rossi T, Boccassini B, Esposito L, Iossa M, Ruggiero A, Tamburrelli C, Bonora N. The pathogenesis of retinal damage in blunt eye trauma: Finite element modeling. Invest Ophthalmol Vis Sci. 2011;52(7):3994-4002.

[PMID:21330659]

http://dx.doi.org/10.1167/iovs.10-6477

5. Duke-Elder WS. Concussion injuries. In: Textbook of ophthalmology. Vol. 6. London (United Kingdom): Henry Kimpton; 1954. p. 5751-5961.

6. Cockerham GC, Rice TA, Hewes EH, Cockerham KP, Lemke S, Wang G, Lin RC, Glynn-Milley C, Zumhagen L. Closed-eye ocular injuries in the Iraq and Afghanistan wars. N Engl J Med. 2011;364(22):2172-73.

[PMID:21631351] http://dx.doi.org/10.1056/NEJMc1010683

7. Capó-Aponte JE, Urosevich TG, Temme LA, Tarbett AK, Sanghera NK. Visual dysfunctions and symptoms during the subacute stage of blast-induced mild traumatic brain injury. Mil Med. 2012;177(7):804-13. [PMID:22808887] http://dx.doi.org/10.7205/MILMED-D-12-00061

8. Capó-Aponte JE, Urosevich TG, Walsh DV, Temme LA, Tarbett AK. Pupillary light reflex as an objective biomarker for early identification of blast-induced mTBI. J Spine. 2013;2(S4):004.

9. Dougherty AL, MacGregor AJ, Han PP, Heltemes KJ, Galarneau MR. Visual dysfunction following blast-related 
traumatic brain injury from the battlefield. Brain Inj. 2011; 25(1):8-13. [PMID:21117919]

http://dx.doi.org/10.3109/02699052.2010.536195

10. Goodrich GL, Flyg HM, Kirby JE, Chang CY, Martinsen GL. Mechanisms of TBI and visual consequences in military and veteran populations. Optom Vis Sci. 2013;90(2): 105-12. [PMID:23314131] http://dx.doi.org/10.1097/OPX.0b013e31827f15a1

11. Lew HL, Garvert DW, Pogoda TK, Hsu PT, Devine JM, White DK, Myers PJ, Goodrich GL. Auditory and visual impairments in patients with blast-related traumatic brain injury: Effect of dual sensory impairment on Functional Independence Measure. J Rehabil Res Dev. 2009;46(6): 819-26. [PMID:20104405] http://dx.doi.org/10.1682/JRRD.2008.09.0129

12. Petras JM, Bauman RA, Elsayed NM. Visual system degeneration induced by blast overpressure. Toxicology. 1997;121(1):41-49. [PMID:9217314]

13. Hines-Beard J, Marchetta J, Gordon S, Chaum E, Geisert EE, Rex TS. A mouse model of ocular blast injury that induces closed globe anterior and posterior pole damage. Exp Eye Res. 2012;99:63-70. [PMID:22504073] http://dx.doi.org/10.1016/j.exer.2012.03.013 Erratum in: Exp Eye Res. 2014;127:301.

14. Zou YY, Kan EM, Lu J, Ng KC, Tan MH, Yao L, Ling EA. Primary blast injury-induced lesions in the retina of adult rats. J Neuroinflammation. 2013;10(1):79. [PMID:23819902] http://dx.doi.org/10.1186/1742-2094-10-79

15. Win-Hall DM, Houser J, Glasser A. Static and dynamic accommodation measured using the WAM-5500 Autorefractor. Optom Vis Sci. 2010;87(11):873-82.

[PMID:20852450]

http://dx.doi.org/10.1097/OPX.0b013e3181f6f98f

16. St. Onge P, McIlwain DS, Hill ME, Walilko TJ, Bardolf LB. Marine Corps Breacher Training Study: Auditory and vestibular findings. US Army Med Dep J. 2011:97-107. [PMID:21805461]

17. Tate CM, Wang KK, Eonta S, Zhang Y, Carr W, Tortella FC, Hayes RL, Kamimori GH. Serum brain biomarker level, neurocognitive performance, and self-reported symptom changes in soldiers repeatedly exposed to low-level blast: A breacher pilot study. J Neurotrauma. 2013;30(19): 1620-30. [PMID:23687938] http://dx.doi.org/10.1089/neu.2012.2683

18. Marine breacher training [Internet]. Marine Corps Base Quantico. Available from: http://www.quantico.marines.mil

19. Rabin J. Quantification of color vision with cone contrast sensitivity. Vis Neurosci. 2004;21(3):483-85.

[PMID:15518234] http://dx.doi.org/10.1017/S0952523804213128

20. Rabin J, Gooch J, Ivan D. Rapid quantification of color vision: The cone contrast test. Invest Ophthalmol Vis Sci.
2011;52(2):816-20. [PMID:21051721]

http://dx.doi.org/10.1167/iovs.10-6283

21. Patel N. The use of frequency doubling technology to determine magnocellular pathway deficiencies. J Behav Optom. 2004;15(2):31-36.

22. Anderson AJ, Johnson CA. Frequency-doubling technology perimetry. Ophthalmol Clin North Am. 2003;16(2): 213-25. [PMID:12809159] http://dx.doi.org/10.1016/S0896-1549(03)00011-7

23. Liesegang TJ. Physiologic changes of the cornea with contact lens wear. CLAO J. 2002;28(1):12-27. [PMID:11838985]

24. McCarey BE, Edelhauser HF, Lynn MJ. Review of corneal endothelial specular microscopy for FDA clinical trials of refractive procedures, surgical devices, and new intraocular drugs and solutions. Cornea. 2008;27(1):1-16.

[PMID:18245960]

http://dx.doi.org/10.1097/ICO.0b013e31815892da

25. Bergmanson JP. Histopathological analysis of corneal endothelial polymegethism. Cornea. 1992;11(2):133-42. [PMID:1582216] http://dx.doi.org/10.1097/00003226-199203000-00007

26. Phillips C, Laing R, Yee R. Specular microscopy. In: Krachmer J, Mannis M, Holland E, editors. Cornea. 2nd ed. Philadelphia (PA): Elsevier Mosby; 2005. p. 261-77.

27. Tzekov R, Quezada A, Gautier M, Biggins D, Frances C, Mouzon B, Jamison J, Mullan M, Crawford F. Repetitive mild traumatic brain injury causes optic nerve and retinal damage in a mouse model. J Neuropathol Exp Neurol. 2014; 3(4):345-61. [PMID:24607965]

http://dx.doi.org/10.1097/NEN.0000000000000059

28. Scheiman M, Mitchell GL, Cotter S, Cooper J, Kulp M, Rouse M, Borsting E, London R, Wensveen J; Convergence Insufficiency Treatment Trial Study Group. A randomized clinical trial of treatments for convergence insufficiency in children. Arch Ophthalmol. 2005;123(1): 14-24. [PMID:15642806]

http://dx.doi.org/10.1001/archopht.123.1.14

29. Cockerham GC, Goodrich GL, Weichel ED, Orcutt JC, Rizzo JF, Bower KS, Schuchard RA. Eye and visual function in traumatic brain injury. J Rehabil Res Dev. 2009; 46(6):811-18. [PMID:20104404] http://dx.doi.org/10.1682/JRRD.2008.08.0109

30. Magone MT, Kwon E, Shin SY. Chronic visual dysfunction after blast-induced mild traumatic brain injury. J Rehabil Res Dev. 2014;51(1):71-80. [PMID:24805895] http://dx.doi.org/10.1682/JRRD.2013.01.0008

31. Doble JE, Feinberg DL, Rosner MS, Rosner AJ. Identification of binocular vision dysfunction (vertical heterophoria) in traumatic brain injury patients and effects of individualized prismatic spectacle lenses in the treatment of postconcussive symptoms: A retrospective analysis. PM R. 2010; 
2(4):244-53. [PMID:20430325]

http://dx.doi.org/10.1016/j.pmrj.2010.01.011

32. Matheron E, Lê TT, Yang Q, Kapoula Z. Effects of a twodiopter vertical prism on posture. Neurosci Lett. 2007; 423(3):236-40. [PMID:17709195]

http://dx.doi.org/10.1016/j.neulet.2007.07.016

33. Walsh DV, Capó-Aponte JE, Jorgenson-Wagers K, Temme LA, Goodrich G, Sosa J, Riggs DW. Visual field dysfunctions in warfighters during different stages following blast and nonblast mTBI. Mil Med. 2015;180(2):178-85.

[PMID:25643385]

http://dx.doi.org/10.7205/MILMED-D-14-00230

34. Chauhan BC, Johnson CA. Test-retest variability of frequency-doubling perimetry and conventional perimetry in glaucoma patients and normal subjects. Invest Ophthalmol Vis Sci. 1999;40(3):648-56. [PMID:10067968]
Submitted for publication September 1, 2014. Accepted in revised form February 6, 2015.

This article and any supplementary material should be cited as follows:

Capó-Aponte JE, Jurek GM, Walsh DV, Temme LA, Ahroon WA, Riggs DW. Effects of repetitive low-level blast exposure on visual systems and ocular structures. J Rehabil Res Dev. 2015;52(3):273-90.

http://dx.doi.org/10.1682/JRRD.2014.09.0204

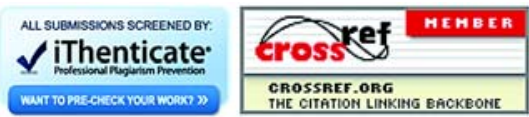

